\title{
Amine Functionalization of Cholecyst-derived Extracellular Matrix with Generation 1 PAMAM Dendrimer
}

Jeffrey C. Y. Chan $\uparrow+$ Krishna Burugapalli†, Hemantkumar Naik†, John L. Kelly $\$$, Abhay Pandit $\uparrow *$

$\uparrow$ National Centre for Biomedical Engineering Science, National University of Ireland,

$\$$ Department of Plastic and Reconstructive Surgery, University College Hospital, Galway, Republic of Ireland.

* To whom correspondence should be addressed

E-mail: abhay.pandit@ nuigalway.ie, Fax: +353 91563991 


\begin{abstract}
A method to functionalize cholecyst-derived extracellular matrix (CEM) with free amine groups was established in an attempt to improve its potential for tethering of bioactive molecules. CEM was incorporated with Generation-1 polyamidoamine (G1 PAMAM) dendrimer by using N-(3-dimethylaminopropyl)-N'-ethylcarbodiimide (EDC) and N-hydroxysuccinimide (NHS) crosslinking system. The nature of incorporation of PAMAM dendrimer was evaluated using shrink temperature measurements, FTIR assessment, ninhydrin assay and swellability. The effect of PAMAM incorporation on mechanical and degradation properties of CEM were evaluated using uniaxial mechanical test and collagenase degradation assay, respectively. Ninhydrin assay and FTIR assessment confirmed the presence of increasing free amine groups with increasing quantity of PAMAM in dendrimer-incorporated CEM (DENCEM) scaffolds. The amount of dendrimer used was found to be critical in controlling scaffold degradation, shrink temperature and free amine content. Cell culture studies showed that fibroblasts seeded on DENCEM maintained their metabolic activity and ability to proliferate in vitro. In addition, fluorescence cell staining and SEM analysis of cell-seeded DENCEM showed preservation of normal fibroblast morphology and phenotype.
\end{abstract}




\section{Introduction}

Intact extracellular matrices (ECM) have demonstrated potential as biomaterials in various tissue engineering and clinical applications. ${ }^{1-3}$ These ECM scaffolds provide a natural three-dimensional support to aid the initial mechanical requirements necessary to support damaged or excised tissue. ${ }^{4-6}$ In addition, ECM provides vital biological cues for cellular recognition which is essential for initial cellular attachment, subsequent cellular differentiation, in growth of vascular networks and secretion of new ECM requisite for eventual scaffold remodeling and tissue regeneration.,

Certain bioactive molecules such as basic fibroblast growth factor (FGF-2), transforming growth factor-beta (TGF-ß) and epidermal growth factor (EGF) are intrinsically found in ECM. ${ }^{9-12}$ In fact, TGF-ß in ECM substrates have been shown to be biologically active even after processing and sterilisation. ${ }^{13}$ As an alternative to the present approach of utilizing endogenous growth factors found naturally in ECM, exogenous biomolecules could be strategically tethered and delivered via ECM substrates when a specific bioactive molecule is desired to provide a specific signal for guided tissue regeneration. ${ }^{14-16}$

In an optimal scaffold, biological functionalities can be provided within the scaffold with the intent to guide tissue regeneration. ${ }^{17,18}$ This could be achieved by passive loading, entrapment or direct covalent binding onto functional groups within scaffolds. ${ }^{19-21}$ Reactive surface functionality of dendrimers make them an attractive candidate as a strategy to deliver bioactive molecules. Dendrimer can function both as a linker to the scaffold and a carrier of bioactive molecules. The dense functional groups terminated on surface of dendrimers can react with intrinsic functional groups in protein- 
based scaffolds to form covalent binding. Conveniently in this way, scaffold stability can also be tailored by controlling the extent of crosslinking, which has the benefit of extending their in vivo life. ${ }^{22,23}$ Availability of multiple functional groups effectively amplifies the number of sites available for conjugation with exogenous bioactive molecules. A similar strategy using polypropyleneimine octaamine dendrimers has recently been employed to stabilize and biofunctionalize collagen intended for cornea replacement. ${ }^{24,25}$ Nevertheless, dendrimers have gained popularity as drug carriers in pharmaceutical research to improve the efficiency of drug delivery. ${ }^{26-28}$

In this study, Generation 1 polyamidoamine (G1 PAMAM) dendrimer was used as a model dendrimer and incorporated into cholecyst-derived extracellular matrix (CEM), a novel intact extracellular matrix derived from the perimuscular subserosal connective tissue of porcine cholecysts developed in our laboratory. ${ }^{4,29,30}$ The influence of different quantity of PAMAM dendrimer on properties of resultant scaffolds was examined. The characteristics of the resultant scaffold were evaluated using shrink temperature measurement, FTIR, ninhydrin assay, uniaxial tensile testing, collagenase degradation assay, as well as in vitro cell studies to ascertain cell viability, proliferation and morphology.

\section{Experimental Section}

Materials and Reagents. All materials and reagents used in this study were purchased from Sigma Ireland Ltd. (Dublin, Ireland) unless otherwise stated. Fresh porcine cholecysts of market-weight pigs were obtained from a local abattoir (Sean Duffy Exports Ltd., Gort, Ireland) and transported in ice to the laboratory.

\section{Preparation of Scaffolds}


Isolation and Decellularization of CEM. CEM isolation process was performed as previously described. ${ }^{29}$ Briefly, excess liver tissue was removed and bile fluid drained. The neck and fundus of the cholecyst were trimmed, followed by a longitudinal incision to obtain a flat sheet of tissue. The mucosa, lamina propria and muscularis layers were peeled from the luminal side, followed by a similar process to remove the serosal mesothelium and its underlying connective tissue from the abluminal side. Any residual elements were removed by mechanical delamination on both sides. A solution of $0.15 \%$ per-acetic acid and $4.8 \%$ ethanol solution in deionized water were used to decellularize the sheet of tissue for $30 \mathrm{~min}$ to obtain the final material. The final material which is referred to as CEM was washed and freeze-dried for storage (Virtis Advantage Freeze Dryer, Gardiner, NY).

PAMAM Incorporation in CEM. To incorporate PAMAM dendrimer in CEM, the freeze dried CEM samples weighing about $0.1 \mathrm{~g}$ were first hydrated in $0.05 \mathrm{M}$ of 2morpholinoethane sulfonic acid (MES) buffer ( $\mathrm{pH}$ 5.3) for $30 \mathrm{~min}$ and then transferred to $50 \mathrm{ml}$ of pre-cooled MES buffer on ice, with or without PAMAM dendrimer. A range of PAMAM dendrimer was used $(0,0.35,0.7,2.1,4.2,6.3,8.4$ mmoles per mg of CEM samples) to vary the degree of dendrimer incorporation. After $30 \mathrm{~min}$ equilibration of CEM samples in dendrimer solution, 0.0066 mmoles of EDC (N-(3dimethylaminopropyl)-N'-ethylcarbodiimide) and NHS (N-hydroxysuccinimide) were added per mg of CEM (molar ratio EDC:NHS of 1:1). The pH was adjusted to 5.3 with 1 $\mathrm{N} \mathrm{NaOH}$ and/or $1 \mathrm{~N} \mathrm{HCl}$. Crosslinking was allowed to begin at $37{ }^{\circ} \mathrm{C}$ in an incubator for 4 hours with intermittent shaking. At the end of the reaction, all resultant samples were washed in three changes of PBS, followed by deionized water and freeze-dried. The 
dendrimer incorporated CEM scaffolds were designated as DENCEM. DENCEM was followed by a numerical suffix indicating the initial feed concentration of PAMAM dendrimer. For example CEM scaffold incorporated with $0.35 \mathrm{mmol}$ of dendrimer/mg of CEM is designated as DENCEM0.35. CEM cross-linked with EDC/NHS without dendrimer is designated as EDCXCEM. Non-cross-linked CEM is designated as CEM.

Glutaraldehyde Crosslinked CEM. Glutaraldehyde crosslinking was used as negative control for cell culture studies, as previously described. ${ }^{29}$ Briefly, $0.4 \mathrm{~g}$ of CEM scaffolds were immersed in $30 \mathrm{ml}$ of $0.625 \%(\mathrm{w} / \mathrm{v})$ of glutaraldehyde in phosphate buffer $(\mathrm{pH} 7.4)$ for 4 hours in room temperature. The samples (GAxCEM) were then washed in PBS followed by distilled water and freeze-dried.

\section{Characterization of Scaffolds}

Shrink Temperature $\left(T_{s}\right)$. The $\mathrm{T}_{\mathrm{s}}$ of the scaffolds were determined using differential scanning calorimetry (DSC, Model DSC-60, Shimadzu, Europe Ltd., Duisburg, Germany). Samples measuring approximately $5 \mathrm{mg}$ were immersed in deionized water at $4{ }^{\circ} \mathrm{C}$ for 1 hour. Excess water was removed from the hydrated samples with filter paper. The moist samples were hermetically sealed in aluminum pans. A constant heating rate of $5{ }^{\circ} \mathrm{C} / \mathrm{min}$ was used (temperature range $25-110^{\circ} \mathrm{C}$ ). An empty aluminum pan was used as the reference pan. $\mathrm{T}_{\mathrm{s}}$ was determined as the onset value of the occurring endothermic peak. The mean value and standard deviation of three independent measurements were obtained for each scaffold type.

Infrared Spectroscopy. IR spectra were recorded at room temperature $\left(26 \pm 1^{\circ} \mathrm{C}\right)$ in the mid infrared range $\left(4000-400 \mathrm{~cm}^{-1}\right)$ using attenuated total reflectance fourier transform infrared spectrometer, (ATR-FTIR) (FTIR-8300, Shimadzu Europe Ltd., 
Duisburg, Germany). Typically, 50 scans were signal-averaged for a single spectrum at a resolution of $\pm 8 \mathrm{~cm}^{-1}$ using a ZnSe crystal at an incident angle of $45^{\circ}$. The spectra were analyzed using the Hyper-IR software (Shimadzu Europe Ltd., Duisburg, Germany) to obtain quantitative peak information.

Ninhydrin Assay. For ninhydrin assay, about $2 \mathrm{mg}$ of each freeze dried test scaffold was taken in separate $1.5 \mathrm{ml}$ microcentrifuge tubes. To each tube was added 200 ul of deionized water and $1 \mathrm{ml}$ of ninhydrin solution (one part of 4\% (w/v) ninhydrin in 2-Ethoxyethanol and one part $200 \mathrm{mM}$ citric acid with $0.16 \%$ (w/v) stannous chloride, $\mathrm{pH}$ 5.0). The tubes were heated at $95{ }^{\circ} \mathrm{C}$ for $30 \mathrm{~min}$ on a heating block. A deep blue or purple color chromophore (Ruhemann's purple) was obtained. The tubes were cooled to room temperature and $250 \mathrm{ul}$ of the cooled solution was added to $1 \mathrm{ml}$ of $50 \%(\mathrm{v} / \mathrm{v})$ isopropanol solution in water. This mixture was vortexed and the optical absorbance of the solution was recorded with a spectrophotometer (UV 1601 - Shimadzu Europe Ltd., Duisburg, Germany) at a wavelength of $570 \mathrm{~nm}$. Glycine at various concentrations was used as standard.

Scaffold Swelling. Approximately 8-10 mg dry weights $\left(\mathrm{W}_{\mathrm{d}}\right)$ of each scaffold types were immersed in Dulbecco's Modified Eagle's Medium (DMEM) at $37^{\circ} \mathrm{C}$. After 24 hours, the scaffolds were dabbed lightly on a piece of absorbent paper to remove excess media. The wet weights $\left(\mathrm{W}_{\mathrm{w}}\right)$ of the scaffolds were measured. Swelling ratio was calculated by using the formula: $\left(\mathrm{W}_{\mathrm{w}-}-\mathrm{W}_{\mathrm{d}}\right) / \mathrm{W}_{\mathrm{w}}$.

Collagenase Degradation. Bacterial collagenase (Type II, from Clostridium histolyticum) (Sigma: C6885, EC 3.4.24.3) was dissolved in 0.1 M Tris- $\mathrm{HCl}$ buffer (pH 7.4) containing $0.005 \mathrm{M} \mathrm{CaCl}_{2}$ and $0.05 \mathrm{mg} / \mathrm{ml} \mathrm{NaN}$. A concentration of 10 units of 
collagenase per mg of scaffold was used. At fixed time points, the degradation process was stopped by snap freezing. The microtubes containing the remaining scaffold were centrifuged at $12,000 \mathrm{rpm}$ for $15 \mathrm{~min}$. The remaining pellet was repeatedly washed with distilled water and subsequently dried and weighed.

Uniaxial Mechanical Testing. 10mm wide strips of each scaffold type were soaked in phosphate buffer saline $(\mathrm{pH}$ 7.4) for at least 10 min. The wet strips were mounted onto a Zwick mechanical test frame fitted with manual clamps (25mm apart).

Five preload cycles $(0.1 \mathrm{~N}$ upper force limit) were applied to each strips to precondition the samples before the final test to failure. After preconditioning, the strips were loaded to failure (100N static load cell, test speed $5 \mathrm{~mm} / \mathrm{min})$. Load/ extension data were logged throughout testing to failure, using a computer equipped with mechanical testing data acquisition and analysis software (testXpert v7.1). These data were used to construct a load-deformation curve, from which the maximum load at failure $\left(\mathrm{F}_{\max }\right)$ was obtained.

In order to grip the samples sufficiently but not damage them with the manual clamps, sandpaper was super-glued to the ends of the samples, with a $10 \mathrm{~mm}$ overlap on each side. This allowed the samples to be clamped securely and concomitantly prevent them from slipping out of the clamps.

The ultimate tensile strength (UTS) ( $F_{\max } /$ original cross-sectional area, $\mathrm{N} / \mathrm{mm}^{2}$ ) and modulus of elasticity (from the relationship $\sigma=\mathrm{E} \varepsilon$, where: $\sigma$ is the stress, $\varepsilon$ is the strain and $\mathrm{E}$ is the modulus of elasticity, $\mathrm{N} / \mathrm{mm}^{2}$ ) and strain at UTS were then determined.

\section{Cell Studies}

Cell Seeding. Murine 3T3 fibroblast were cultured to confluence in T75 flask containing DMEM which was supplemented with $10 \%$ fetal bovine serum (FBS), $1 \%$ 
(v/v) penicillin-streptomycin, $1.25 \mathrm{mg} / \mathrm{L}$ Amphotericin-B and $1 \%$ glutamine $200 \mathrm{mM}$. Freeze dried test scaffolds were cut to fit the base of a 24 -well plate (12 mm diameter). The scaffolds were disinfected with $0.15 \%$ per-acetic acid in $4.8 \%$ ethanol solution for 10 min and subsequently washed thoroughly with Hank's Balanced Salt Solution (HBSS). The samples were then incubated in media for 1 hour in a $5 \% \mathrm{CO}_{2}$ humidified incubator at $37^{\circ} \mathrm{C}$ prior to seeding. Each scaffold was seeded with a density of 20000 cells per well. Media was changed every 24 hours.

AlamarBlue $^{\mathrm{TM}}$ Assay. The viability of 3T3 fibroblasts on the test scaffolds was studied by monitoring their metabolic activity using the AlamarBlue ${ }^{\mathrm{TM}}$ assay (Biosource International, CA). At 1, 3, and 7 days after seeding, all cell-seeded scaffolds were transferred to a fresh 24-well plate to exclude the possibility of contribution of cells which might have proliferate at the bottom of the well. The scaffolds were rinsed with HBSS and $700 \mathrm{ul}$ of $10 \%(\mathrm{v} / \mathrm{v})$ AlamarBlue ${ }^{\mathrm{TM}}$ reagent in HBSS was added to each well. After $1 \mathrm{~h}$ of incubation at $37^{\circ} \mathrm{C}$, fluorescence was measured using a microplate fluorescence reader (FLx800, Bio-Tek Instruments, Inc., Vermont) at excitation and emission wavelengths of 528 and $590 \mathrm{~nm}$. Non-crosslinked CEM, EDCxCEM, tissue culture polystyrene (TCP, empty wells) and $0.625 \%$ glutaraldehyde (GAxCEM) crosslinked samples were used as control scaffolds.

Hoechst Assay. The proliferation of 3T3 fibroblasts on CEM scaffolds were studied by quantifying the DNA on the cell-seeded scaffolds using the calorimetric Hoechst assay (bis-benzimide 33258). A working solution (concentration of $1 \mathrm{ug} / \mathrm{ml}$ ) was made in Dulbecco's Phosphate Buffered Saline (DPBS). At 3 and 6 days after seeding, the cell-seeded scaffolds were transferred to a fresh 24-well plate and $1 \mathrm{ml}$ of 
water was added to each well. Three freeze-thaw cycles (freeze at $-80{ }^{\circ} \mathrm{C}$, thaw to room temperature) were used to lyse the cell membranes followed by gentle shaking to release DNA into solution. 40 ul of cell lysate was transferred from each well into a 96-well plate and $160 \mathrm{ul}$ of Hoechst solution was added. The mixture was allowed to sit for $20 \mathrm{~min}$ in the dark and the fluorescence was measured at $355 \mathrm{~nm}$ (excitation) and $460 \mathrm{~nm}$ (emission) (Wallac Victor3, 1420 Multilabel Counter, Perkin Elmer Inc., Wellesley, MA, USA). Calf Thymus DNA (Sigma D-4764) was used as a standard. Non-crosslinked CEM, EDCxCEM and $0.625 \%$ glutaraldehyde crosslinked (GAxCEM) samples were used as control scaffolds.

Cell Morphology - Scanning Electron Microscopy (SEM). Murine $3 \mathrm{~T} 3$ fibroblasts were grown on CEM scaffolds for 7 days with changes in media every 24 hours. The cellseeded scaffolds were washed twice with HBSS. The scaffolds were fixed with $3 \%$ GA for 24 hours followed by a standard process of dehydration in graded ethanol and chemical drying with hexamethyldisilazane. The dried samples were gold-coated (Emitech K-550X Sputter Coater, Emitech Ltd., Ashford, Kent, UK). A low-voltage, high resolution SEM (S-4700 Hitachi Scientific Instruments, Berkshire, UK) was used to acquire micrographs of cells on the surface of CEM scaffolds.

Cell Morphology - Fluorescent Staining. Scaffolds seeded with cells were fixed with $4 \%$ paraformaldehyde for $15 \mathrm{~min}$. The cells were permeabilized with $0.2 \%$ Triton X100 and cell cytoskeleton stained with rhodamine phalloidin (Molecular Probes, Bio Sciences Ltd., Dublin, Ireland) using 1:100 dilution for $1 \mathrm{~h}$ at room temperature. Excess stain was rinsed using HBSS and 4',6-diamidino-2-phenylindole (DAPI, Vectashield Mounting Medium with DAPI, H-1500, Vector Laboratories, Peterborough, UK) was 
used to stain the nuclei of cells for $20 \mathrm{~min}$. The stained cells on scaffolds were rinsed in HBSS and were examined under fluorescence light microscope (BX51 inverted microscope equipped with DP-70 photography system, Olympus Europe, Hamburg, Germany). ImagePro Plus 5.0 software (Media Cybenetics Inc., MD, USA) was used to acquire digital images from the microscope.

Statistical Analysis. Statistical differences between experimental groups was determined by one-way analysis of variance (ANOVA). Tukey's test was used for post hoc multiple comparisons. T-test was used when data had only two independent groups. A $p$ value of $<0.05$ was considered to be statistically significant. Data are reported as the mean \pm SD. SPSS 14.0 software for Microsoft Windows was used for this statistical analysis.

\section{Results}

\section{Characterization of Scaffolds.}

Shrink Temperature $\left(T_{s}\right)$. $\mathrm{T}_{\mathrm{s}}$ is a measure of the hydrothermal stability of collagen

based scaffolds. The higher the shrink temperature, the higher the crosslinking. ${ }^{31,32}$ Figure 1 illustrates the $\mathrm{T}_{\mathrm{s}}$ results for CEM, EDCxCEM and DENCEM scaffolds. Crosslinking of CEM with $0.0066 \mathrm{mM}$ of EDC both in the presence and absence of amine dendrimer, significantly increased the shrink temperature. Compared to EDCxCEM, addition of increasing feed concentrations of amine dendrimer did not cause a continuous increase in shrink temperature of DENCEM samples. Small quantities of PAMAM increased the $T_{s}$, but only up to a feed concentration of 0.7 mmoles of PAMAM per mg CEM. Beyond this concentration lower $\mathrm{T}_{\mathrm{s}}$ were observed and were significantly lower for DENCEM6.3 and DENCEM8.4. 
The initial increase in $\mathrm{T}_{\mathrm{s}}$ from $70.0 \pm 0.8^{\circ} \mathrm{C}$ for $\mathrm{EDCxCEM}$ to $72.7 \pm 0.4^{\circ} \mathrm{C}$ for DENCEM0.7 can be attributed to the augmentation of crosslinking process by the multi amine dendrimer. In contrast, when dendrimer feed concentrations $>0.7$ mmoles per $\mathrm{mg}$ CEM were used, the drop in the $\mathrm{T}_{\mathrm{s}}$ to $63.9 \pm 0.8^{\circ} \mathrm{C}$ observed with DENCEM8.4 can be attributed to the excess dendrimer molecules competing for fewer available carboxyl groups causing less crosslink bridges and more pendant dendrimer molecules on CEM.

Infrared Spectroscopy. IR spectroscopy involves the measurement of wavelength and intensity of absorption of IR light through excitation of molecular vibrations, which provides predictive information about changes in molecular structure of organic materials. ATR-FTIR has been a useful tool in the prediction of protein structure and crosslinking. The representative IR spectra of the test scaffolds in this study are shown in Figure 2A. All spectra were typical of that observed for proteins ${ }^{33-35}$ and it was difficult to distinguish any trends or changes in the spectra among the scaffold variants by naked eye. In order to analyze the spectra, quantitative peak information was obtained using the Hyper-IR software (Shimatzu, Japan). The absorption peak area ratios of the Amide I band at $1635 \mathrm{~cm}^{-1}$ to that of free $-\mathrm{COOH}$ group at $1735 \mathrm{~cm}^{-1}$ were determined and the ratios plotted as a function of dendrimer feed concentration (Figure 2B). The rationale behind the choice of the peaks $1635 \mathrm{~cm}^{-1}$ and $1735 \mathrm{~cm}^{-1}$ was that the amount of EDC activated $-\mathrm{COOH}$ groups available for reaction are constant because of the use of a fixed amount of EDC (0.0066 mmoles of EDC per mg CEM) in the preparation for all DENCEM samples. As a result, an increase in the $1635 \mathrm{~cm}^{-1}$ to $1735 \mathrm{~cm}^{-1}$ peak ratios would indicate the decrease in the free $-\mathrm{COOH}$ groups and the increase in amide linkages. The Amide I $\left(1635 \mathrm{~cm}^{-1}\right)$ to free $-\mathrm{COOH}\left(1735 \mathrm{~cm}^{-1}\right)$ peak area ratio for 
DENCEM scaffolds increased with increasing dendrimer concentration until 4.2 mmoles and decreased with further increase in dendrimer concentration (Figure 2B).

Ninhydrin Assay. Ninhydrin assay was used to quantitatively assess the amount of free amines present in the scaffolds. ${ }^{36,37}$ The results of the quantitative assessment of amine content using colorimetric ninhydrin assay are shown in Figure 3. EDC/ NHS crosslinking of CEM reduced the amount of free amine groups by amide bond formation with carboxyl groups. All DENCEM scaffolds showed significantly higher free amine groups when compared to both EDCxCEM and non-crosslinked CEM, with the exception of DENCEM0.35 compared to non-crosslinked CEM. Among the DENCEM scaffolds, the free amine content increased with increasing PAMAM dendrimer reaction feed concentration, indicating an increasing incorporation of free amine groups within the scaffold.

Scaffold Swelling. The swelling ratio shows the hydrophilicity of the engineered constructs, as well as the ability to hold fluid and nutrients in both the in vitro and in vivo environments, factors which are important for cellullar infiltration and proliferation. Additionally, it represents a crude assessment of the extent of crosslinking as reported earlier. ${ }^{38,39}$ The swelling ratios for the scaffold variants of this study in DMEM media at $37^{\circ} \mathrm{C}$ at 24 hours are presented in Figure 4. The non-crosslinked CEM control showed the highest swelling ratio. All DENCEM samples and EDCxCEM showed a statistically lower swelling ratio compared to non-crosslinked CEM indicating crosslinking of CEM scaffold.

Collagenase Degradation. Collagenase degradation assay has been used to evaluate the resistance of collagen-based scaffolds against enzymatic degradation. ${ }^{40,41}$ 
The percentage weight of scaffolds remaining after collagenase degradation as a function of time is shown in Figure 5. At 8 hours, EDCxCEM, DENCEM0.35 and DENCEM0.70 scaffolds showed significantly higher resistance to degradation when compared to DENCEM4.2 and DENCEM8.4 scaffolds. DENCEM8.4 showed significant difference with all other scaffolds at 8 hours. As expected, non-crosslinked CEM control showed significantly lower remaining weight when compared to all other scaffolds at 8 hours. At 48 hours, DENCEM0.35 and DENCEM0.7 still showed higher resistance to degradation when compared to other scaffolds and all samples were eventually degraded with no intact scaffold at 72 hours.

Uniaxial Mechanical Testing. The ultimate tensile strength (UTS), modulus of elasticity and strain at UTS of CEM, EDCxCEM and DENCEM scaffolds are shown in Table 1. Crosslinking had no significant effect on the ultimate tensile strength of CEM. However, differences were observed for modulus of elasticity and strain at UTS of noncrosslinked CEM from rest of the scaffold variants. The modulus of elasticity was significantly lower and strain at UTS significantly higher for EDCxCEM and DENCEM scaffolds compared to that observed for non-crosslinked CEM, with the exception of DENCEM0.35 for modulus of elasticity. Among EDCxCEM and DENCEM scaffolds no statistical differences were observed for both modulus of elasticity and strain at UTS, with the exception of DENCEM6.3, which showed a significantly higher strain at UTS.

\section{Cell Studies.}

AlamarBlue $^{\text {TM }}$ Assay. The results of the Alamar-Blue cell viability assay of fibroblasts seeded on CEM, EDCxCEM \& DENCEM scaffolds compared to that on TCP (positive control) and GAxCEM (negative control) as measured by fluorescence optical 
density (OD) are shown in Figure 6. No statistical differences of AlamarBlue OD were observed on CEM, EDCxCEM, and DENCEM scaffolds compared to that on TCP, except a significantly higher OD for TCP at 3 days, whereas the ODs for all scaffolds at all time points were significantly higher than that on GAxCEM. From day 1 to day 7 , there was a significant increase in AlamarBlue OD all test variants, with the exception of TCP and DENCEM0.35 between day 3 and day 7. In the case of GAxCEM, the OD decreased significantly after day 1 .

Hoechst Assay. Figure 7 shows the results of DNA content by Hoechst DNA assay. All scaffolds showed increased DNA content from day 3 to day 6, with the exception of GAxCEM. At day 3, DENCEM and EDCXCEM scaffolds showed significantly lower DNA content when compared to non-cross-linked CEM, except DENCEM6.3 which showed no difference. At day 6, the DENCEM6.3 showed significantly higher DNA content than all other scaffolds. Within the DENCEM samples, there was an increase in DNA content with increase in dendrimer feed concentration.

Cell Morphology. The SEM and fluorescent light micrographs of scaffolds seeded with 3T3 fibroblast cells are shown in Figure 8. SEM images illustrate the surface morphology of confluent fibroblasts at 7 days on scaffolds. The morphology of fibroblasts on DENCEM (Figure 8e-h) and EDCxCEM (Figure 8c,d) scaffolds was similar to that observed on non-cross-linked CEM (Figure 8a,b). The fluorescent light micrographs showed intact cytoskeleton and nuclei of fibroblast cells. In less confluent areas, the fibroblasts could be seen to attach to each other and onto the three-dimensional surface of the scaffold fibers by elongated dendritic projections. The fibroblast cell bodies 
were typically either round, elongated, or star-shaped. Some cells showed an elongated appearance and attached along scaffold fibers (Figure 8d-f).

\section{Discussion}

In the present study, decellularized extracellular matrix from the porcine cholecyst was incorporated with G1 PAMAM dendrimers and the properties of the resultant scaffolds (DENCEM) were evaluated. In order to facilitate covalent attachment of the amine dendrimer onto the CEM scaffold, the carbodiimide (EDC/ NHS) crosslinking system was employed. The nature of incorporation of dendrimers was evaluated using shrink temperature, ATR-FTIR, ninhydrin and swelling studies. The effect of dendrimer incorporation on the mechanical, degradation and in vitro ability to support cell attachment, viability and proliferation properties of CEM were studied by uniaxial testing, collagenase degradation and in vitro cell culture, respectively.

We had previously shown that the CEM scaffold contains approximately $80 \%$ of collagen and therefore, provides the required carboxyl and amine groups for amide crosslinking. ${ }^{29}$ Since the quantity of amine groups in collagen (34/1000 amino acid residues) is much lower than the quantity of carboxylic groups (120/1000 amino acid residues), ${ }^{38}$ it is desirable to provide additional amine groups in the form of amine dendrimer to augment the crosslinking process. Other research groups have investigated the effect of diamines as a method to improve compatibility and the extent of crosslinking in collagen. ${ }^{42-44}$ Our hypothesis for this study was that by using the multiamine PAMAM dendrimer, any unreacted amine groups in dendrimer can be utilized to tether bioactive molecules to improve chemical and biological functionalities of the scaffold. 
EDC/ NHS crosslinking involves the formation of amide bond between the carboxyl groups of glutamic or aspartic acid residues and amine groups. ${ }^{38,45}$ EDC is a water-soluble, zero-length crosslinker, whose reaction by-products can be eliminated by buffer/ water washing. ${ }^{45}$ Therefore, the EDC/NHS crosslinking does not leave any cytotoxic residues on the crosslinked matrix. ${ }^{46-49}$

The EDC crosslinker concentration used in current experiments was kept constant at 0.0066 mmoles per mg of CEM and the amount of PAMAM dendrimer varied. The choice of 0.0066 mmoles of EDC/NHS per mg of scaffold was based on our earlier study. ${ }^{50}$ At this concentration, the in vitro collagenase degradation time of CEM was prolonged, while maintaining degradability over an extended period of time, and any higher concentrations of EDC/ NHS resulted in total inhibition of CEM degradation by collagenase enzyme. ${ }^{50}$ In the present study, setting the EDC crosslinking concentration constant allowed us to study the effect of varying dendrimer concentration on the properties of CEM.

The current study demonstrated the critical role played by the incorporation of varied feed concentration of PAMAM dendrimer on the properties of the resulting CEM scaffolds (DENCEM). G1 PAMAM dendrimer is a multifunctional (eight free amines per molecule) chemical agent, which was used as an adjunct to the EDC/ NHS crosslinking of CEM. In order to form effective bridging crosslinks, each dendrimer molecules must form at least two amide bonds to bridge polypeptides. An initial increase of amine groups of PAMAM allows more bridging crosslinks formation with the carboxyl groups in CEM. When higher or excess quantity of PAMAM dendrimer was used, competition for carboxyl groups occurred, leading to less bridging crosslinks between polypeptides. This 
means that in excess, PAMAM dendrimers are effectively 'blocking' the carboxyl groups from forming bridging crosslink by becoming pendant molecules. Similar observation was reported by Ma et al. when amino acids were used as crosslinking bridge for porous collagen scaffolds. ${ }^{51}$ The authors found that a $\mathrm{NH}_{2}: \mathrm{COOH}$ ratio of between 2-14 to be optimal for achieving stability with collagen scaffolds using a similar crosslinking system of EDC/ NHS. ${ }^{51}$

It is interesting to note from Ts measurements (Figure 1) and collagenase degradation (Figure 5) that crosslinking reached a maximum with 0.7 mmoles of dendrimer. However, ATR-FTIR peak area ratios indicated a maximum utilization of $\mathrm{COOH}$ groups at 4.2 mmoles (Figure $2 \mathrm{~b}$ ). This observation can be explained as 0.7 mmoles of dendrimer causes maximum number of crosslinking bridges and beyond 0.7 mmoles, the tendency for formation of pendant PAMAM increases. At 4.2 mmoles of PAMAM, the $-\mathrm{COOH}$ could be completely utilized both by formation of crosslinking bridges as well as pendant PAMAM. Beyond 4.2 mmoles of PAMAM, the $T_{s}$ and FTIR peak area ratios decreased (Figure 2b), while the amine content increased (Figure 3). That is, an increase in amine content is observed in spite of decrease in number of covalently bonded PAMAM molecules. This phenomenon could be due to inter-dendrimer interactions leading to the formation of oligomeric aggregates of PAMAM molecules at high concentrations. At high concentrations, the PAMAM molecules are reported to be involved in the formation of oligomeric aggregates by both non-specific repulsive interactions (steric plus electrostatic) as well as shorter range attractive interactions. ${ }^{52,53}$ Thus, at high concentrations, the high molecular weight PAMAM oligomeric aggregates would be competing for the free $-\mathrm{COOH}$ groups on CEM. The bulkiness of PAMAM 
oligomers covalently bonded on the CEM could be involved in steric hindrance resulting in reduced crosslinking and under-utilization of $-\mathrm{COOH}$ groups. Furthermore, the oligomeric aggregates indicate an increase in the number of free amines as opposed to monomeric PAMAM at lower concentrations, explaining the increase in free amine content demonstrated by ninhydrin assay.

The degree of swelling of a scaffold network is proportional to the amount of ions present in the network. Crosslinking a scaffold would decrease the swelling by restricting the polymer chain relaxation as well as by decrease in ionizable functional groups on the network. In the current study, we can expect an increase in swelling, as tethering multifunctional PAMAM dendrimer would increase the amount of ionizable $-\mathrm{NH}_{2}$ groups in the CEM network. However, we did not see any statistical difference between the DENCEM scaffold variants (Figure 4). This could be due to the non-ionization of $\mathrm{NH}_{2}$ groups at $\mathrm{pH} 7.4$ of the swelling buffer.

The elastic moduli of crosslinked scaffolds were lower than that of noncrosslinked CEM control, indicating that scaffolds were less stiff after the EDC/ NHS crosslinking process. The complex interactions between extracellular matrix and PAMAM dendrimer may confer the scaffold with increased extensibility without compromising tensile strength. This finding can be advantageous in clinical application where tensile strength and distensibility are essential but stiffness is undesirable, such as a scaffold for repair of the mobile anterior abdominal wall. ${ }^{54,55}$ The extent of crosslinking is generally believed to correspond to physical properties. ${ }^{56}$ The influence of EDC/ NHS crosslinking on mechanical properties of various collagen-based scaffolds has been studied with inconsistent results. While some studies showed improvement in tensile 
strength and stiffness with crosslinking treatment, ${ }^{32,57}$ others have shown the opposite or no effect. ${ }^{31,38,58}$ Duan et al. found that mechanical properties of collagen crosslinked with polypropyleneimine octaamine dendrimers was poor ${ }^{59}$ but improved dramatically by changing the collagen concentration. ${ }^{24}$ It may be that the concentration of EDC/ NHS used in this study was too low to produce any significant effect on tensile strength. Higher concentration of crosslinker might improve mechanical properties but at the expense of degradability.

AlamarBlue $^{\mathrm{TM}}$ and Hoechst DNA assays were used to assess metabolic activity and cell proliferation on cell-seeded scaffolds, respectively. ${ }^{60-62}$ Cells seeded on DENCEM scaffolds maintained their metabolic activity throughout the study period. Significant increase in the metabolic activity was observed with increasing culture time for DENCEM, EDCxCEM and non-crosslinked CEM (Figure 6). This finding was in contrast with the glutaraldehyde crosslinked negative control (GAxCEM), which showed a significantly lower metabolic activity. With increasing culture time, a significant reduction in activity was detected on GAxCEM. We have previously shown that glutaraldehyde crosslinking resulted in reduced cell activity compared to non-crosslinked CEM, and hence, the current effort to develop more cytocompatible crosslinking method. ${ }^{29}$ In addition, Hoechst DNA assay results showed that cells proliferated on the scaffolds (Figure 7). These results suggest that when PAMAM dendrimers were incorporated within CEM, their ability to support cell attachment and proliferation was similar to as seen with non-crosslinked CEM. ${ }^{29}$ In addition, the normal fibroblast morphology shown on SEM and fluorescent cell staining indicate that the cell phenotype was preserved (Figure 8). Blue fluorescence from cell nuclei was readily emitted after 
staining with DAPI, indicating abundance of DNA. Actin cytoskeleton was demonstrated by rhodamine phalloidin with concentration at the tips of the cell processes, presumably for cell to cell and cell to scaffold attachments. Cellular dendritic projections play a crucial role for cells in understanding the three dimensional environment and for cell to cell communications. ${ }^{63}$

It should also be noted that scaffolds crosslinked with high quantity of PAMAM were still more stable compared to non-crosslinked CEM in both collagenase degradation and shrink temperature studies. This observation may be beneficial when designing scaffold with specific requirements. Modulation of conditions for PAMAM incorporation offers the opportunity to fabricate scaffold with a predefined degradation profile, shrink temperature and amine functional groups. When rapidly degrading scaffold is needed, high quantity of dendrimer can be used to provide the desired functional sites with the aim to deliver bioactive molecule. In contrast, when a prolonged scaffold presence is required in vivo, lower quantity of dendrimer can be incorporated into the scaffold while still maintaining grafting sites for bioactive molecules. Nevertheless, all crosslinked CEM scaffolds were eventually degraded and solublized in vitro by collagenase enzyme by the end of the study period of 72 hours. It is hypothesized that the difference in degradation profile will be more marked when these scaffolds are implanted in vivo and therefore, has potential for tailoring of in vivo degradation.

In conclusion, incorporation of varied feed concentrations of PAMAM dendrimer in CEM using EDC/ NHS crosslinking system resulted in covalent binding of PAMAM on CEM. Varied degrees of crosslinking, improved stability of CEM to enzymatic degradation, increased amine functional groups useful in tethering bioactive agents, 
maintenance of tensile strength but increased flexibility of scaffold, as well as preservation of the ability of DENCEM to support cells in vitro were observed. These promising results justify the use of dendrimers as a strategy in designing degradable scaffold with predetermined biological functionality. Future studies would include using higher generation dendrimers that could provide higher degree of crosslinking and more free amine groups for subsequent modification.

Acknowledgement. The authors gratefully acknowledge the financial support from Enterprise Ireland (Technology Development Grant). 


\section{References and Notes}

(1) Badylak, S. F. Anat. Rec. B New. Anat. 2005, 287, 36-41.

(2) Badylak, S. F. Biomaterials 2007, 28, 3587-3593.

(3) Hodde, J. Tissue Eng. 2002, 8, 295-308.

(4) Coburn, J. C.; Brody, S.; Billiar, K. L.; Pandit, A. J. Biomed. Mater. Res. 2007, 81A, 250-256.

(5) Kochupura, P. V.; Azeloglu, E. U.; Kelly, D. J.; Doronin, S. V.; Badylak, S. F.; Krukenkamp, I. B.; Cohen, I. S.; Gaudette, G. R. Circulation 2005, 112, I144-I149.

(6) Ko, R.; Kazacos, E. A.; Snyder, S.; Ernst, D. M.; Lantz, G. C. J. Surg. Res. 2006, 135, 9-17.

(7) Badylak, S. F. Semin. Cell. Dev. Biol. 2002, 13, 377-383.

(8) Badylak, S.; Kokini, K.; Tullius, B.; Simmons-Byrd, A.; Morff, R. J. Surg. Res. 2002, 103, 190-202.

(9) Hodde, J. P.; Record, R. D.; Liang, H. A.; Badylak, S. F. Endothelium 2001, $8,11-24$.

(10) Koizumi, N. J.; Inatomi, T. J.; Sotozono, C. J.; Fullwood, N. J.; Quantock, A. J.; Kinoshita, S. Curr. Eye Res. 2000, 20, 173-177.

(11) Meinert, M.; Eriksen, G. V.; Petersen, A. C.; Helmig, R. B.; Laurent, C.; Uldbjerg, N.; Malmstrom, A. Am. J. Obstet .Gynecol. 2001, 184, 679-685.

(12) Voytik-Harbin, S. L.; Brightman, A. O.; Kraine, M. R.; Waisner, B.; Badylak, S. F. J. Cell Biochem. 1997, 67, 478-491.

(13) McDevitt, C. A.; Wildey, G. M.; Cutrone, R. M. J. Biomed. Mater. Res. 2003, 67, 637-640.

(14) Tessmar, J. K.; Gopferich, A. M. Adv. Drug Deliv. Rev. 2007, 59, 274291.

(15) Wissink, M. J.; Beernink, R.; Scharenborg, N. M.; Poot, A. A.; Engbers, G. H.; Beugeling, T.; van Aken, W. G.; Feijen, J. J. Control. Rel. 2000, 67, 141-155.

(16) Tabata, Y.; Ikada, Y. Biomaterials 1999, 20, 2169-2175.

(17) Babensee, J. E.; McIntire, L. V.; Mikos, A. G. Pharm. Res. 2000, 17, 497-

504.

(18) Chen, R. R.; Mooney, D. J. Pharm. Res. 2003, 20, 1103-1112.

(19) Lee, S. H.; Shin, H. Adv. Drug Deliv. Rev. 2007, 59, 339-359.

(20) Malafaya, P. B.; Silva, G. A.; Reis, R. L. Adv. Drug Deliv. Rev. 2007, 59, 207-233.

(21) Sokolsky-Papkov, M.; Agashi, K.; Olaye, A.; Shakesheff, K.; Domb, A. J. Adv. Drug Deliv. Rev. 2007, 59, 187-206.

(22) Liang, H. C.; Chang, Y.; Hsu, C. K.; Lee, M. H.; Sung, H. W. Biomaterials 2004, 25, 3541-3552.

(23) van Wachem, P. B.; Plantinga, J. A.; Wissink, M. J.; Beernink, R.; Poot, A. A.; Engbers, G. H.; Beugeling, T.; van Aken, W. G.; Feijen, J.; van Luyn, M. J. J. Biomed. Mater. Res. 2001, 55, 368-378.

(24) Duan, X.; Sheardown, H. Biomaterials 2006, 27, 4608-4617.

(25) Duan, X.; McLaughlin, C.; Griffith, M.; Sheardown, H. Biomaterials 2007, 28, 78-88. 
(26) Chandrasekar, D.; Sistla, R.; Ahmad, F. J.; Khar, R. K.; Diwan, P. V. Biomaterials 2007, 28, 504-512.

(27) Najlah, M.; Freeman, S.; Attwood, D.; D'Emanuele, A. Int. J. Pharm. 2007, 336, 183-190.

(28) Papagiannaros, A.; Dimas, K.; Papaioannou, G. T.; Demetzos, C. Int. J. Pharm. 2005, 302, 29-38.

(29) Burugapalli, K.; Thapasimuttu, A.; Chan, J. C.; Yao, L.; Brody, S.; Kelly, J. L.; Pandit, A. Biomacromolecules 2007, 8, 928-936.

(30) Brody, S.; McMahon, J.; Yao, L.; O'Brien, M.; Dockery, P.; Pandit, A. Biomaterials 2007, 28, 1461-1469.

(31) Angele, P.; Abke, J.; Kujat, R.; Faltermeier, H.; Schumann, D.; Nerlich, M.; Kinner, B.; Englert, C.; Ruszczak, Z.; Mehrl, R.; Mueller, R. Biomaterials 2004, 25, 2831-2841.

(32) Billiar, K.; Murray, J.; Laude, D.; Abraham, G.; Bachrach, N. J. Biomed. Mater. Res. 2001, 56, 101-108.

(33) Dumas, P.; Miller, L. Vib. Spectrosc. 2003, 32, 3-21.

(34) Wolkers, W. F.; Oliver, A. E.; Tablin, F.; Crowe, J. H. Carbohydr. Res. 2004, 339, 1077-1085.

(35) Yee, N.; Benning, L. G.; Phoenix, V. R.; Ferris, F. G. Environ. Sci. Technol. 2004, 38, 775-782.

(36) Curotto, E.; Aros, F. Anal. Biochem. 1993, 211, 240-241.

(37) Ma, Z.; Gao, C.; Gong, Y.; Shen, J. J. Biomed. Mater. Res. 2003, 67B, 610-617.

(38) Olde Damink, L. H.; Dijkstra, P. J.; van Luyn, M. J.; van Wachem, P. B.; Nieuwenhuis, P.; Feijen, J. Biomaterials 1996, 17, 765-773.

(39) Saito, H.; Taguchi, T.; Aoki, H.; Murabayashi, S.; Mitamura, Y.; Tanaka, J.; Tateishi, T. Acta. Biomater. 2007, 3, 89-94.

(40) Pek, Y. S.; Spector, M.; Yannas, I. V.; Gibson, L. J. Biomaterials 2004, $25,473-482$.

(41) Zhong, S.; Teo, W. E.; Zhu, X.; Beuerman, R.; Ramakrishna, S.; Yung, L. Y. Biomacromolecules 2005, 6, 2998-3004.

(42) McKegney, M.; Taggart, I.; Grant, M. H. J. Mater. Sci. Mater. Med. 2001, $12,833-844$.

(43) Osborne, C. S.; Reid, W. H.; Grant, M. H. J. Mater. Sci. Mater. Med. 1997, 8, 179-184.

(44) Zilla, P.; Bezuidenhout, D.; Torrianni, M.; Hendriks, M.; Human, P. J. Heart Valve Dis. 2005, 14, 538-545.

(45) Lee, J. M.; Edwards, H. H. L.; Pereira, C. A.; Samii, S. I. J. Mater. Sci. Mater. Med. 1996, 7, 531-541.

(46) Pieper, J. S.; Oosterhof, A.; Dijkstra, P. J.; Veerkamp, J. H.; van Kuppevelt, T. H. Biomaterials 1999, 20, 847-858.

(47) van Wachem, P. B.; van Luyn, M. J.; Olde Damink, L. H.; Dijkstra, P. J.; Feijen, J.; Nieuwenhuis, P. J. Biomed. Mater. Res. 1994, 28, 353-363.

(48) van Wachem, P. B.; van Luyn, M. J.; Olde Damink, L. H.; Dijkstra, P. J.; Feijen, J.; Nieuwenhuis, P. Int. J. Artif. Organs 1994, 17, 230-239. 
(49) Wissink, M. J.; van Luyn, M. J.; Beernink, R.; Dijk, F.; Poot, A. A.; Engbers, G. H.; Beugeling, T.; van Aken, W. G.; Feijen, J. Thromb. Haemost. 2000, 84, 325-331.

(50) Chan, J. C. Y.; Burugapalli, K.; Kelly, J. L.; Pandit, A. P. In Conference Proceedings of the 21st European Conference on Biomaterials. Brighton, East Sussex, United Kingdom., 2007.

(51) Ma, L.; Gao, C.; Mao, Z.; Zhou, J.; Shen, J. Biomaterials 2004, 25, $2997-$ 3004.

(52) Domanski, D. M.; Klajnert, B.; Bryszewska, M. Bioelectrochem. 2004, 63, 193-197.

(53) Nourse, A.; Millar, D. B.; Minton, A. P. Biopoly. 2000, 53, 316-328.

(54) DuBay, D. A.; Wang, X.; Adamson, B.; Kuzon, W. M., Jr.; Dennis, R. G.; Franz, M. G. Surgery 2006, 140, 14-24.

(55) Ferrando, J. M.; Vidal, J.; Armengol, M.; Gil, J.; Manero, J. M.; Huguet, P.; Segarra, A.; Quiles, M. T.; Schwartz, S.; Arbos i Via, M. A. World J. Surg. 2002, 26, 409-415.

(56) Charulatha, V.; Rajaram, A. Biomaterials 2003, 24, 759-767.

(57) Buttafoco, L.; Engbers-Buijtenhuijs, P.; Poot, A. A.; Dijkstra, P. J.; Daamen, W. F.; van Kuppevelt, T. H.; Vermes, I.; Feijen, J. J. Biomed. Mater. Res. 2006, $77 B, 357-368$.

(58) Olde Damink, L. H.; Dijkstra, P. J.; van Luyn, M. J.; van Wachem, P. B.; Nieuwenhuis, P.; Feijen, J. Biomaterials 1996, 17, 679-84.

(59) Duan, X.; Sheardown, H. J. Biomed. Mater. Res. 2005, 75A, 510-518.

(60) Unsworth, J. M.; Rose, F. R.; Wright, E.; Scotchford, C. A.; Shakesheff, K. M. J. Biomed. Mater. Res. 2003, 66A, 425-431.

(61) Garcia, Y.; Collighan, R.; Griffin, M.; Pandit, A. J. Mater. Sci. Mater. Med. 2007, 18, 1991-2001.

(62) Henry, J. A.; Simonet, M.; Pandit, A.; Neuenschwander, P. J. Biomed. Mater. Res. 2007, 82A, 669-679.

(63) Grinnell, F.; Ho, C. H.; Tamariz, E.; Lee, D. J.; Skuta, G. Mol. Biol. Cell. 2003, 14, 384-395. 
TABLE 1

\begin{tabular}{|c|c|c|c|}
\hline Scaffold Types & Ultimate $\quad$ Tensile & Modulus of & Strain at UTS (\%) \\
\hline & Strength (UTS) (MPa) & Elasticity (MPa) & \\
\hline CEM & $3.4 \pm 0.5$ & $8.4 \pm 2.3^{a}$ & $32.0 \pm 2.9^{a}$ \\
\hline EDCXCEM & $2.6 \pm 0.4$ & $4.1 \pm 0.4^{b}$ & $56.9 \pm 5.8^{b}$ \\
\hline DENCEM0.35 & $2.5 \pm 0.6$ & $5.1 \pm 2.4$ & $48.5 \pm 19.8^{b}$ \\
\hline DENCEM0.7 & $1.9 \pm 0.7$ & $4.2 \pm 1.1^{b}$ & $48.9 \pm 10.9^{b}$ \\
\hline DENCEM2.1 & $2.7 \pm 0.8$ & $2.8 \pm 0.5^{b}$ & $50.8 \pm 3.7^{b}$ \\
\hline DENCEM6.3 & $3.1 \pm 0.4$ & $1.3 \pm 0.9^{b}$ & $87.6 \pm 13.0^{b}$ \\
\hline
\end{tabular}

${ }^{a}$ indicates statistically significant difference with ${ }^{b}$ by ANOVA, $\mathrm{p}<0.05$.

Table 1. Table showing mean values \pm SD of ultimate tensile strength (UTS), modulus of elasticity and strain at UTS for the scaffold variants tested. 


\section{FIGURE 1}

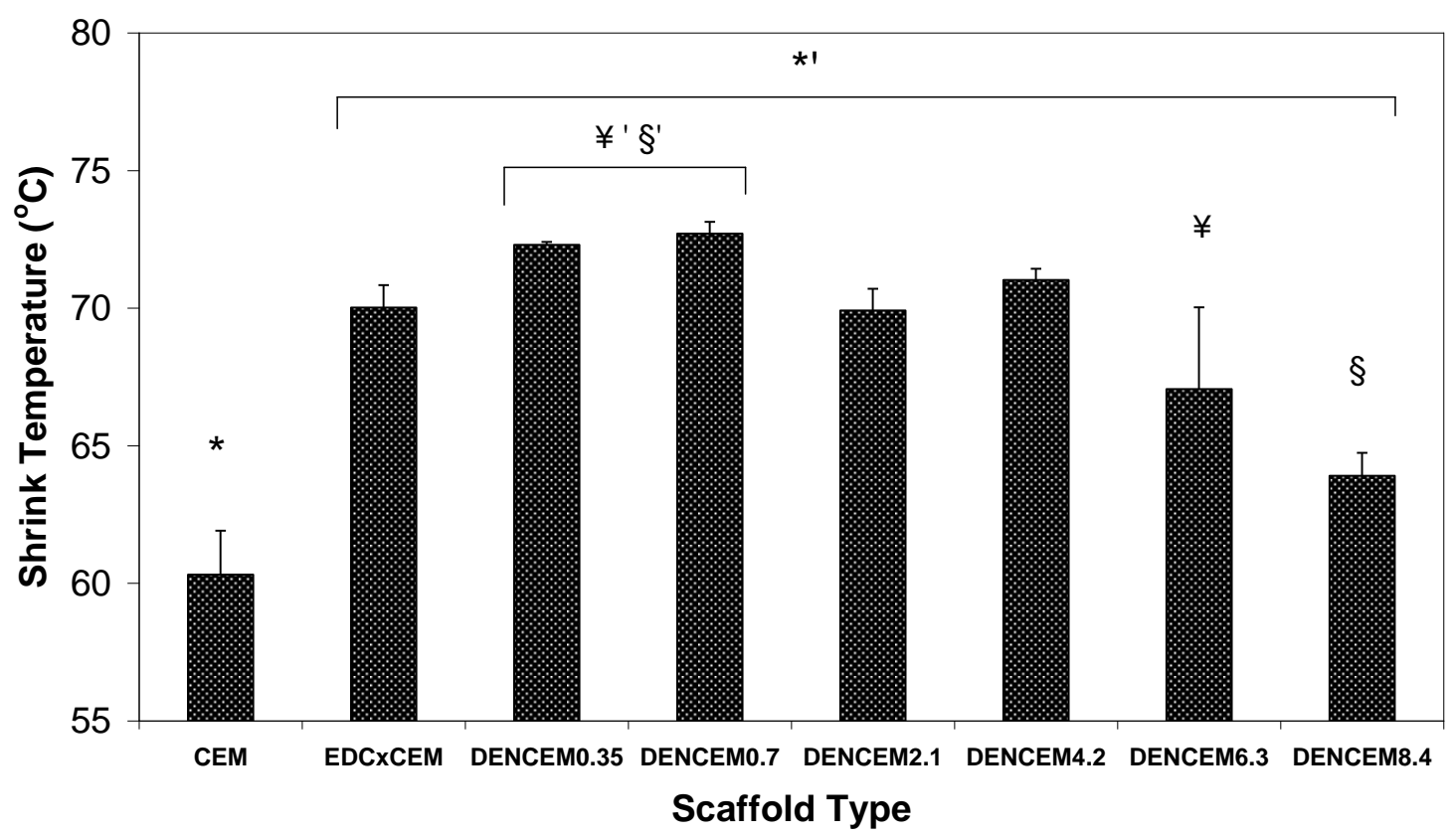

Figure 1. Shrink temperature measurements of CEM, EDCxCEM and DENCEM. $*^{* *}, ¥$ $¥ ’, \S$ ') indicates statistical significance with each other. (ANOVA, $\mathrm{p}<0.05, \mathrm{n}=3$ ). 
FIGURES 2A and 2B
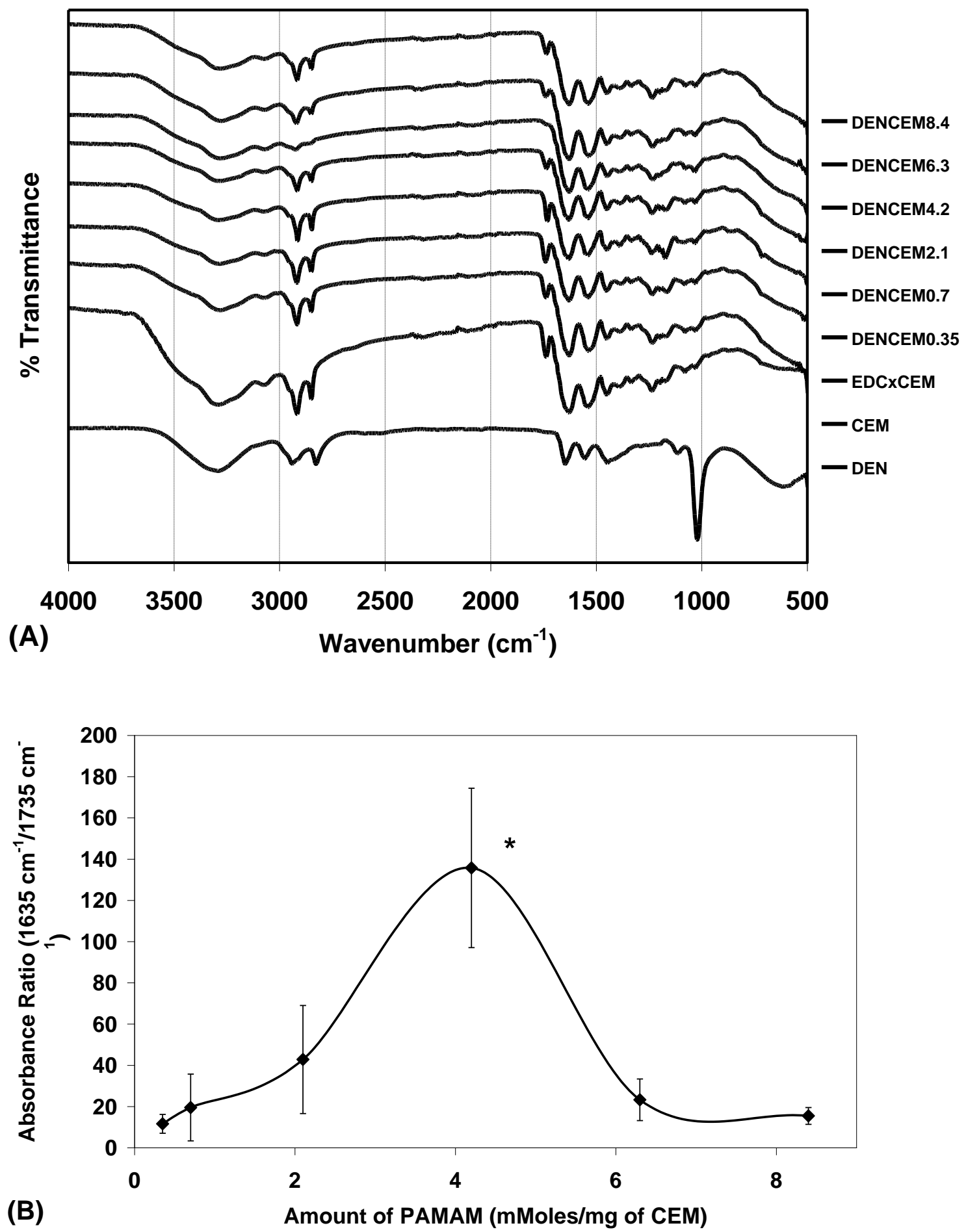
Figure 2. ATR-FTIR results showing (A) representative IR spectra for PAMAM dendrimer (DEN), CEM, DENCEM and EDCXCEM scaffolds and (B) the ratio of absorption intensity of $1631 \mathrm{~cm}^{-1}$ to $1735 \mathrm{~cm}^{-1}$ is plotted against the amount of PAMAM used for incorporation in CEM. * indicates statistical difference from the rest (ANOVA, $p$ $<0.05, \mathrm{n}=3)$. 


\section{FIGURE 3}

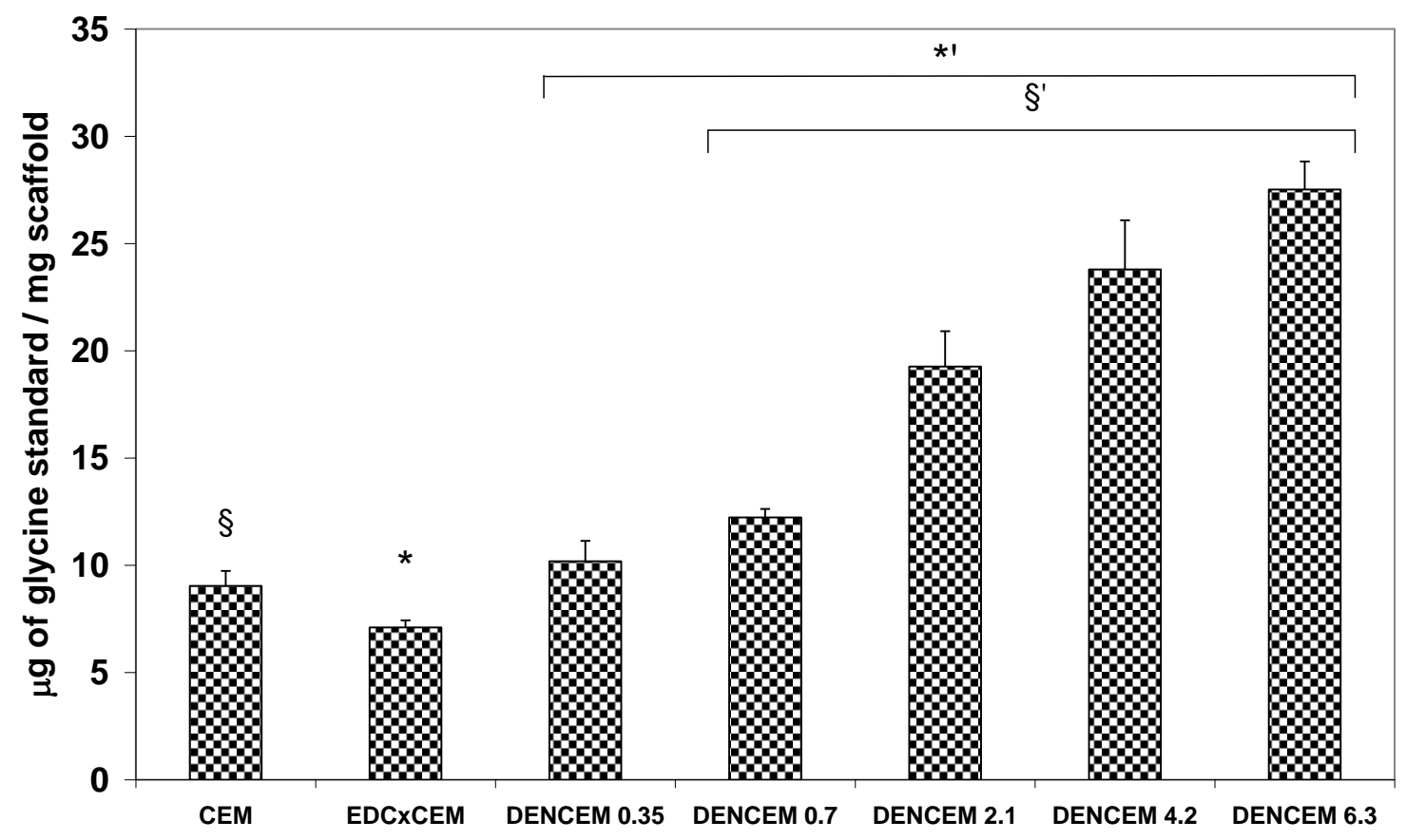

Figure 3. Free amine content measurements expressed in $\mu \mathrm{g}$ of glycine per $\mathrm{mg}$ of scaffold by ninhydrin method. $(* *,, \S \S$ ) indicates statistically significant difference with each other by ANOVA $(n=3)$. 


\section{FIGURE 4}

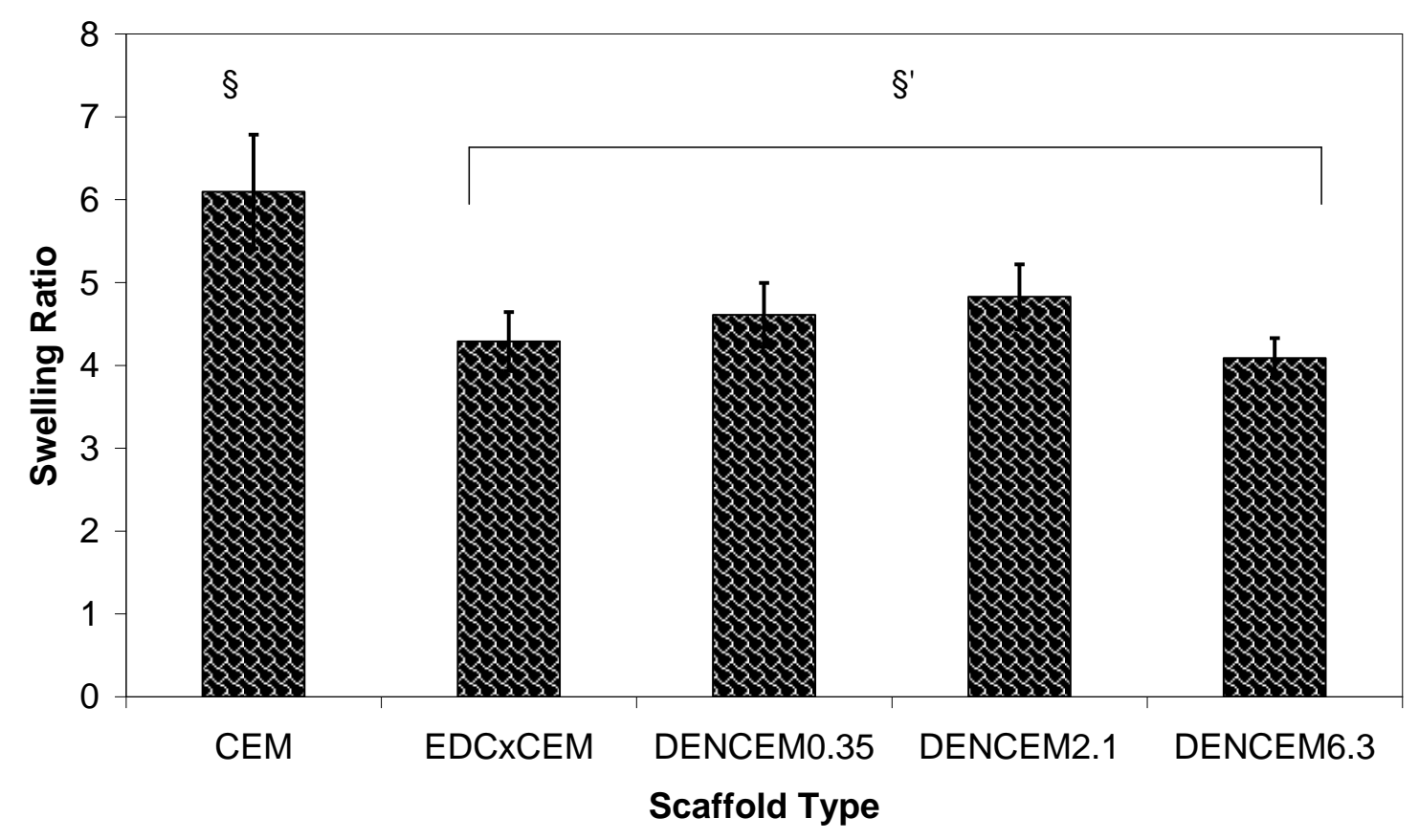

Figure 4. Scaffold swelling behaviour shown as swelling ratio for CEM, EDCxCEM and DENCEM. § §' indicates significant difference with each other $(\mathrm{n}=4)$. 


\section{FIGURE 5}

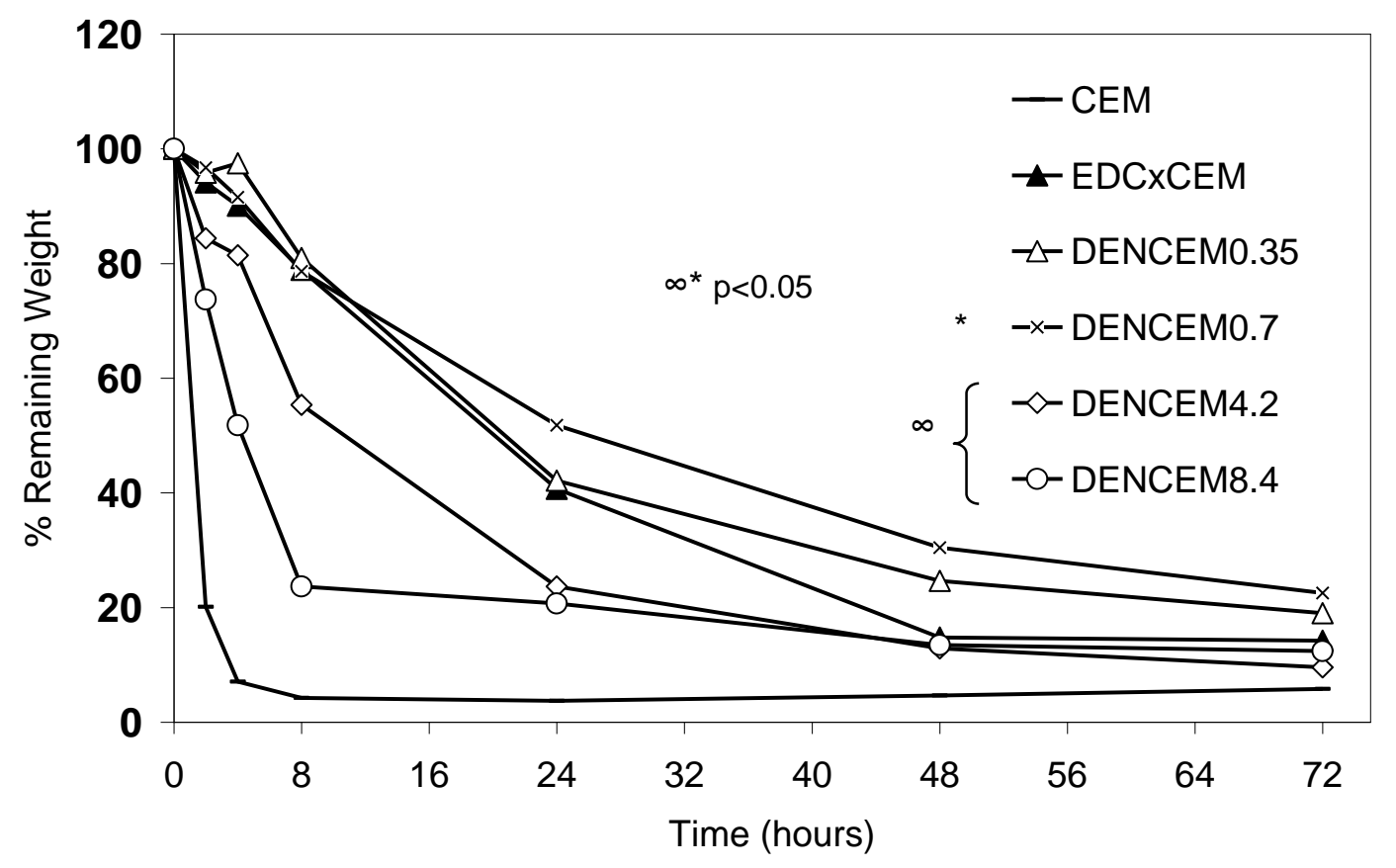

Figure 5. Collagenase degradation assay of DENCEM, EDCXCEM and CEM scaffolds up to 72 hours in vitro. $*_{\infty}$ indicate significant difference in percentage weight remaining at 8 hours (ANOVA, $\mathrm{p}<0.05, \mathrm{n}=3$ ). 
FIGURE 6

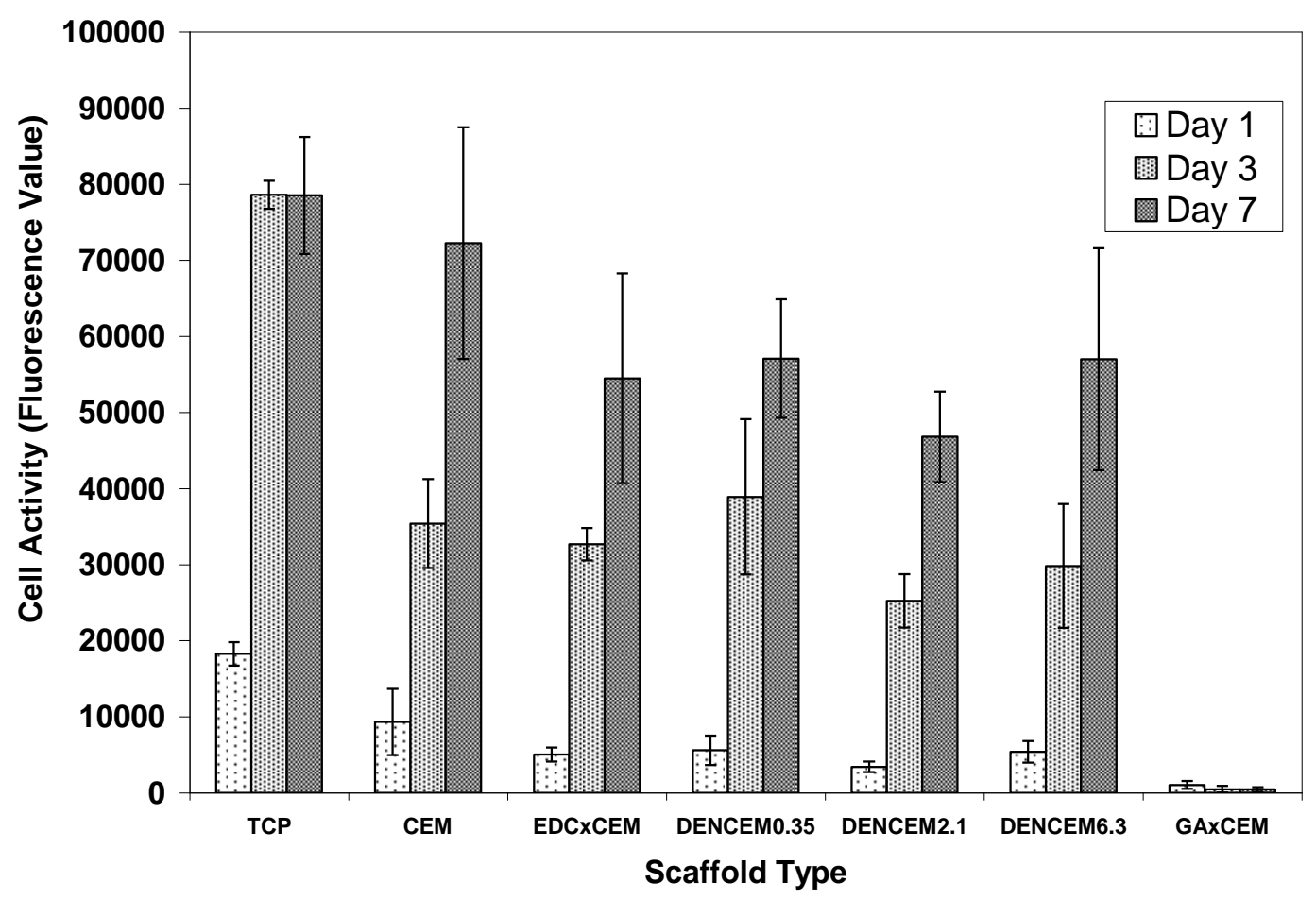

Figure 6. AlamarBlue ${ }^{\mathrm{TM}}$ fluorescence optical density (OD) of fibroblast seeded test scaffolds compared to that on tissue culture plastic (TCP, positive control) and GAxCEM (negative control) as a function of time. 


\section{FIGURE 7}

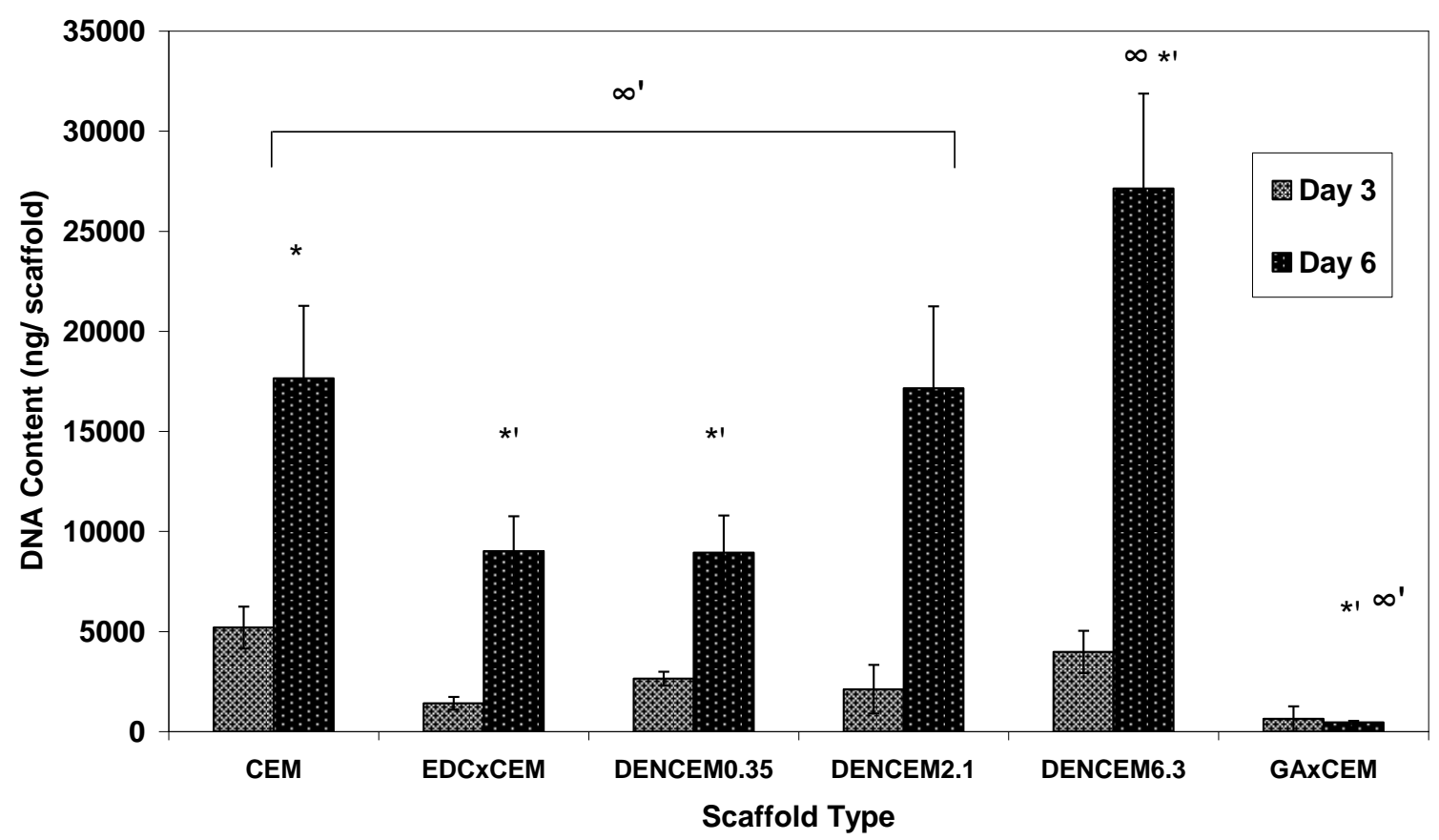

Figure 7. Hoechst DNA assay showing increase in DNA content from day 3 to day 6. With exception of negative control (GAxCEM), all scaffolds showed an increase in DNA content from day 3 to day $\left.6 . *^{* *}\right)$ and ( $\left(\infty^{\prime}\right)$ indicate statistically significant difference between groups. 


\section{FIGURE 8}

Figure 8. SEM and photomicrographs of $3 \mathrm{~T} 3$ fibroblasts seeded on scaffolds showing surface morphology and fluorescent staining (Rhodamine Phalloidin and DAPI) of cytoskeleton and nuclei. Fibroblasts with dendritic-like processes attaching to each other and surrounding extracellular matrix on (a \& b) non-crosslinked CEM, (c) EDCxCEM, and ( $\mathrm{g} \& \mathrm{~h}$ ) DENCEM2.1. Fibroblasts attached on extracellular matrix showing appearance of elongated cell body along direction of fibres on (d) EDCxCEM and (e \& f) DENCEM0.7. 
Figure 8 (a)

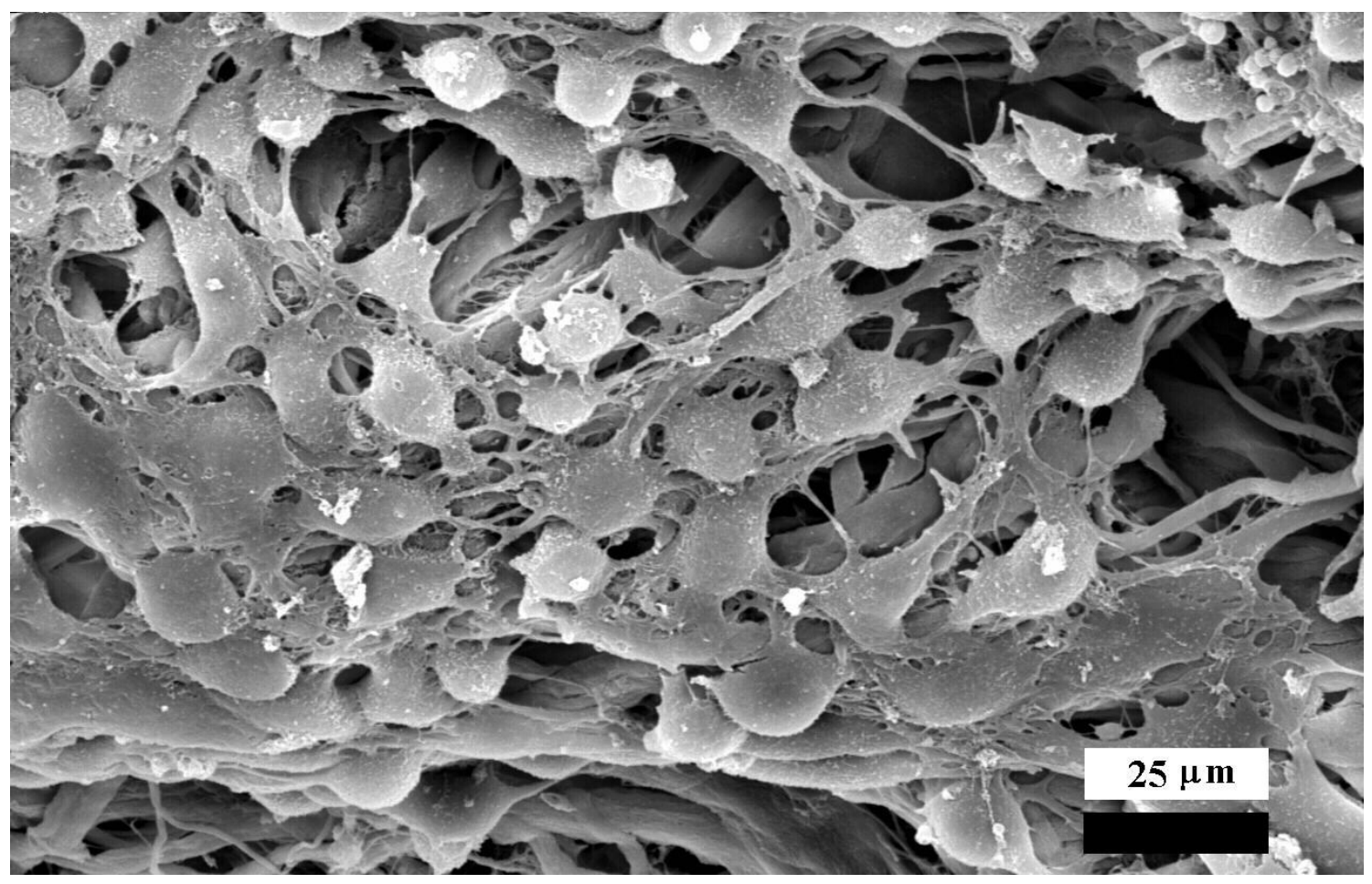

Figure 8 (b)

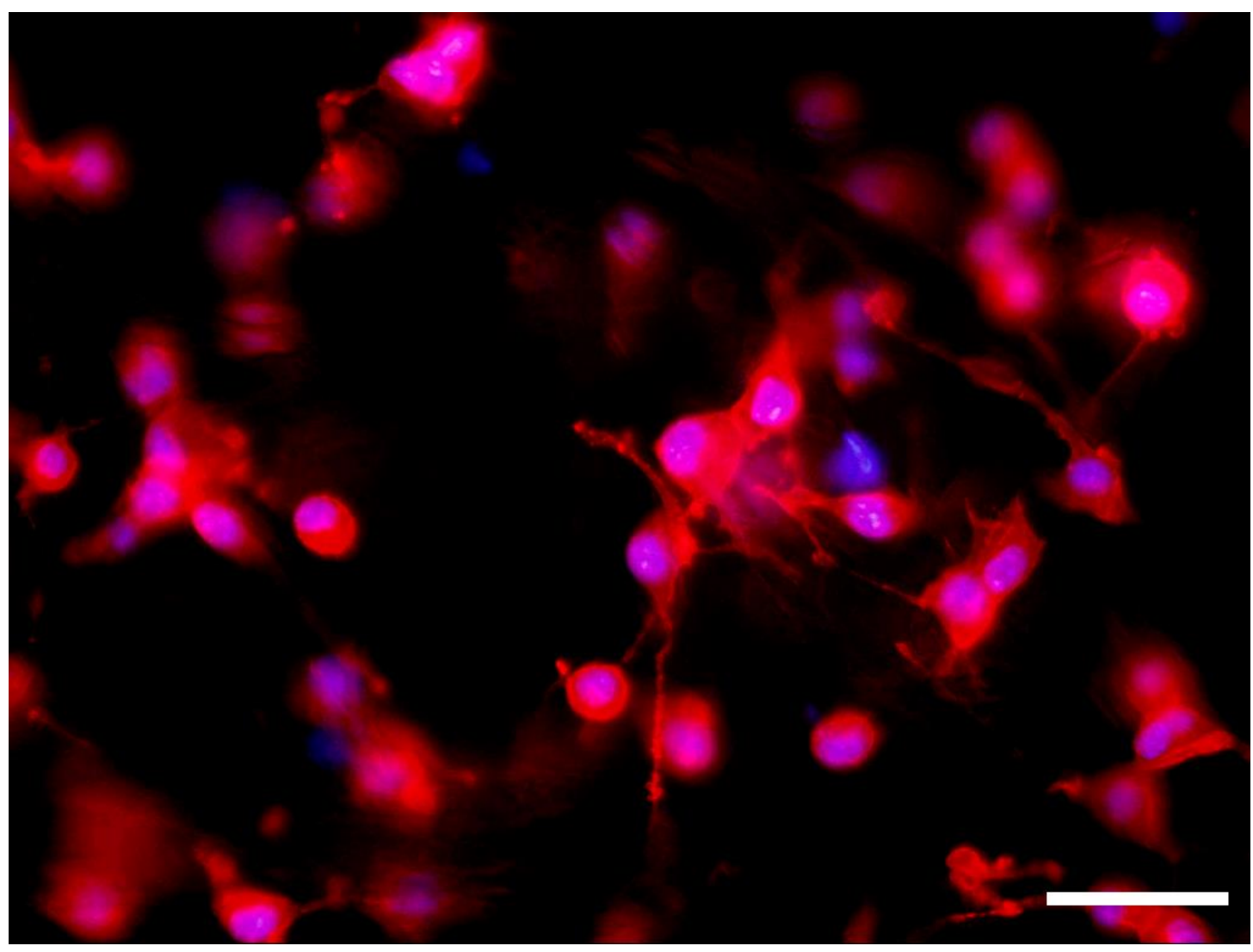


Figure 8 (c)

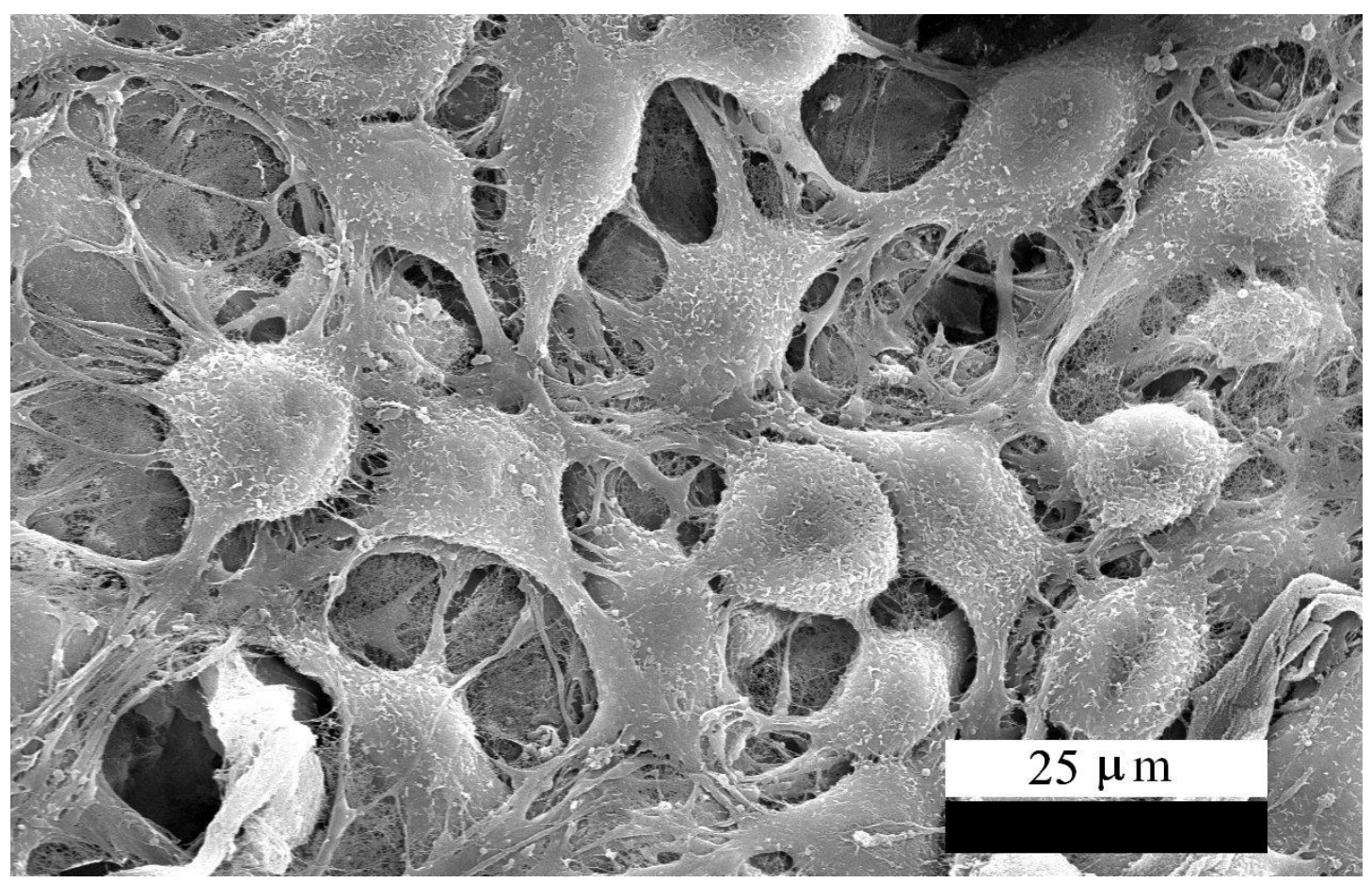

Figure 8 (d)

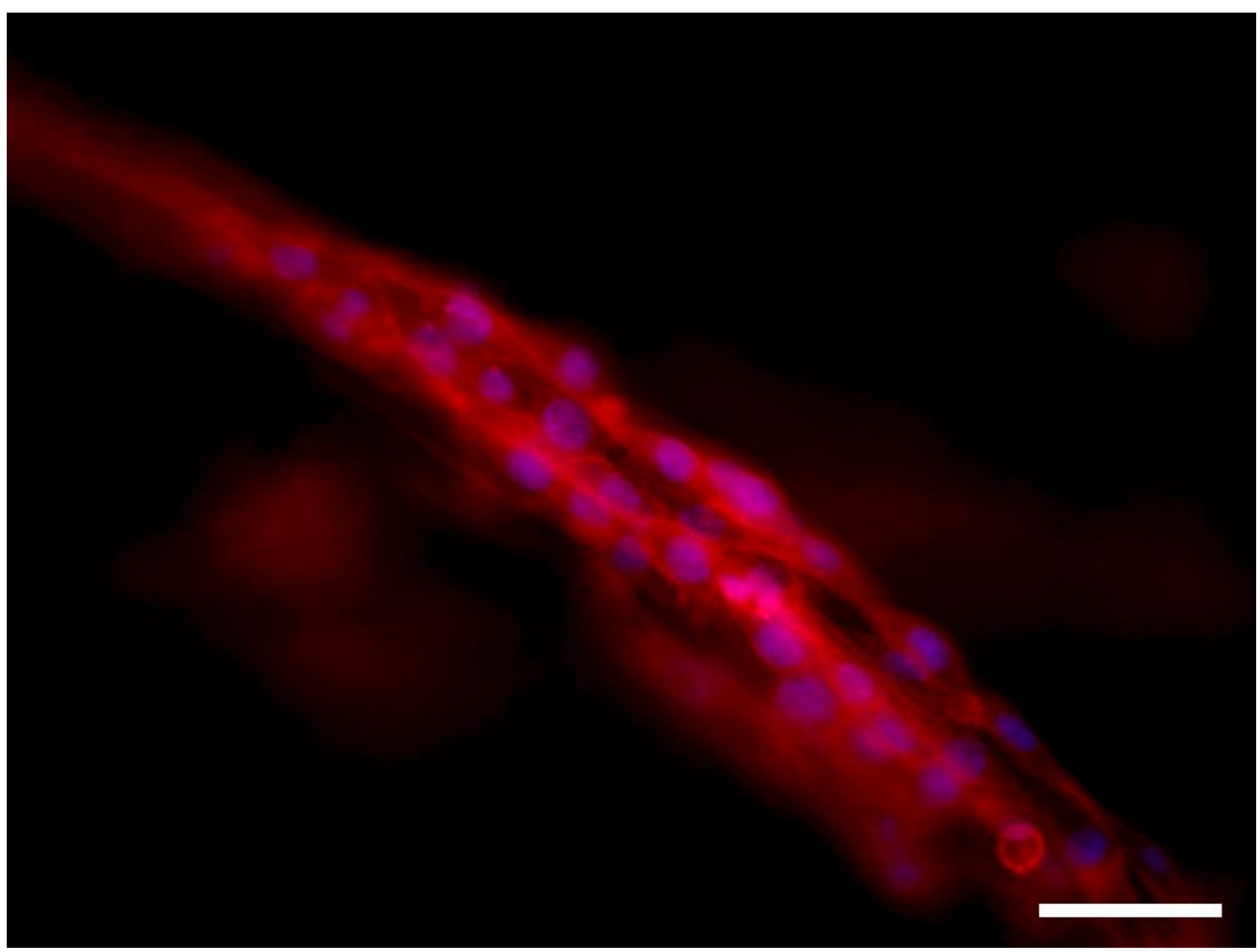


Figure 8 (e)

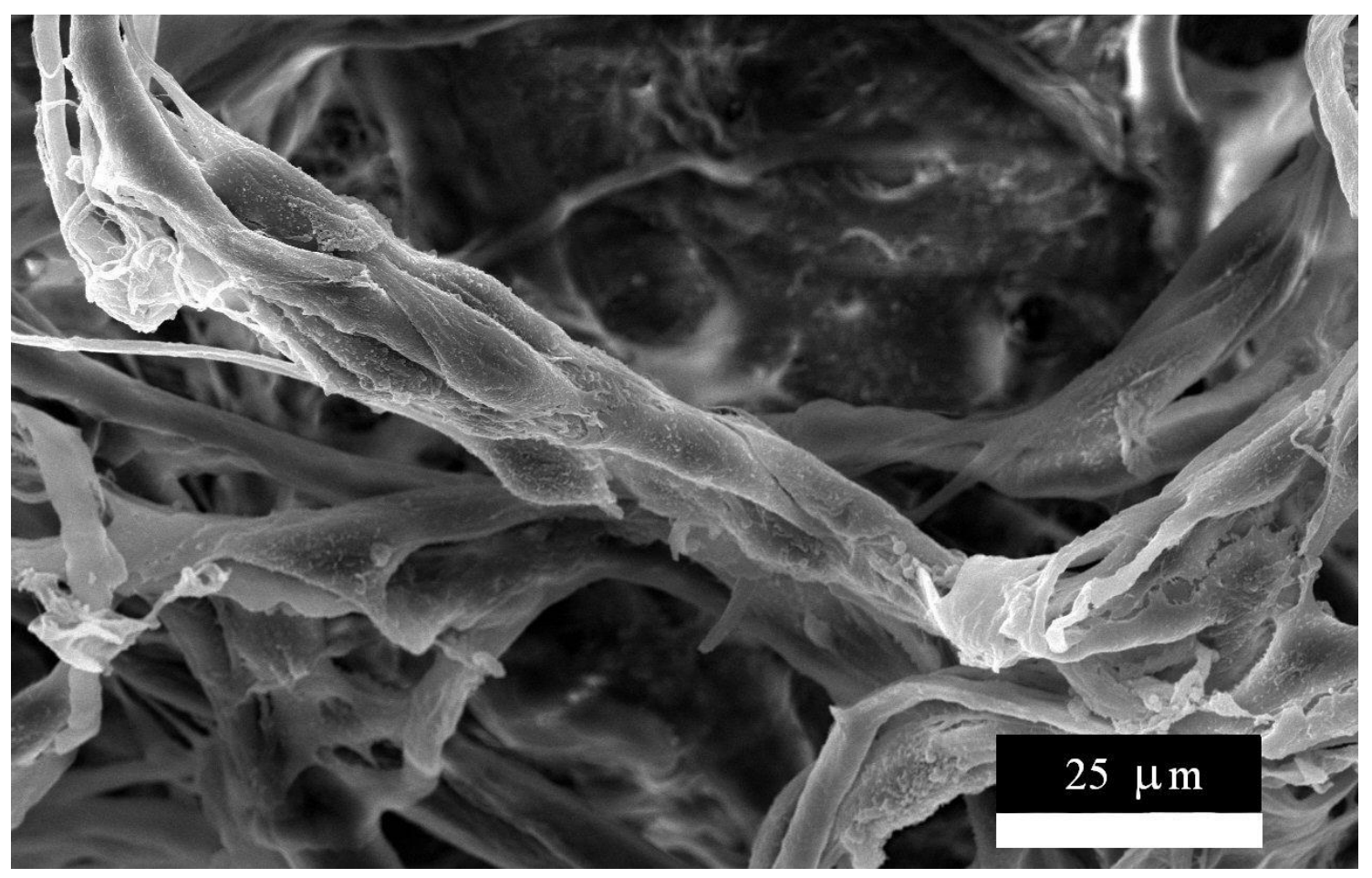

Figure 8 (f)

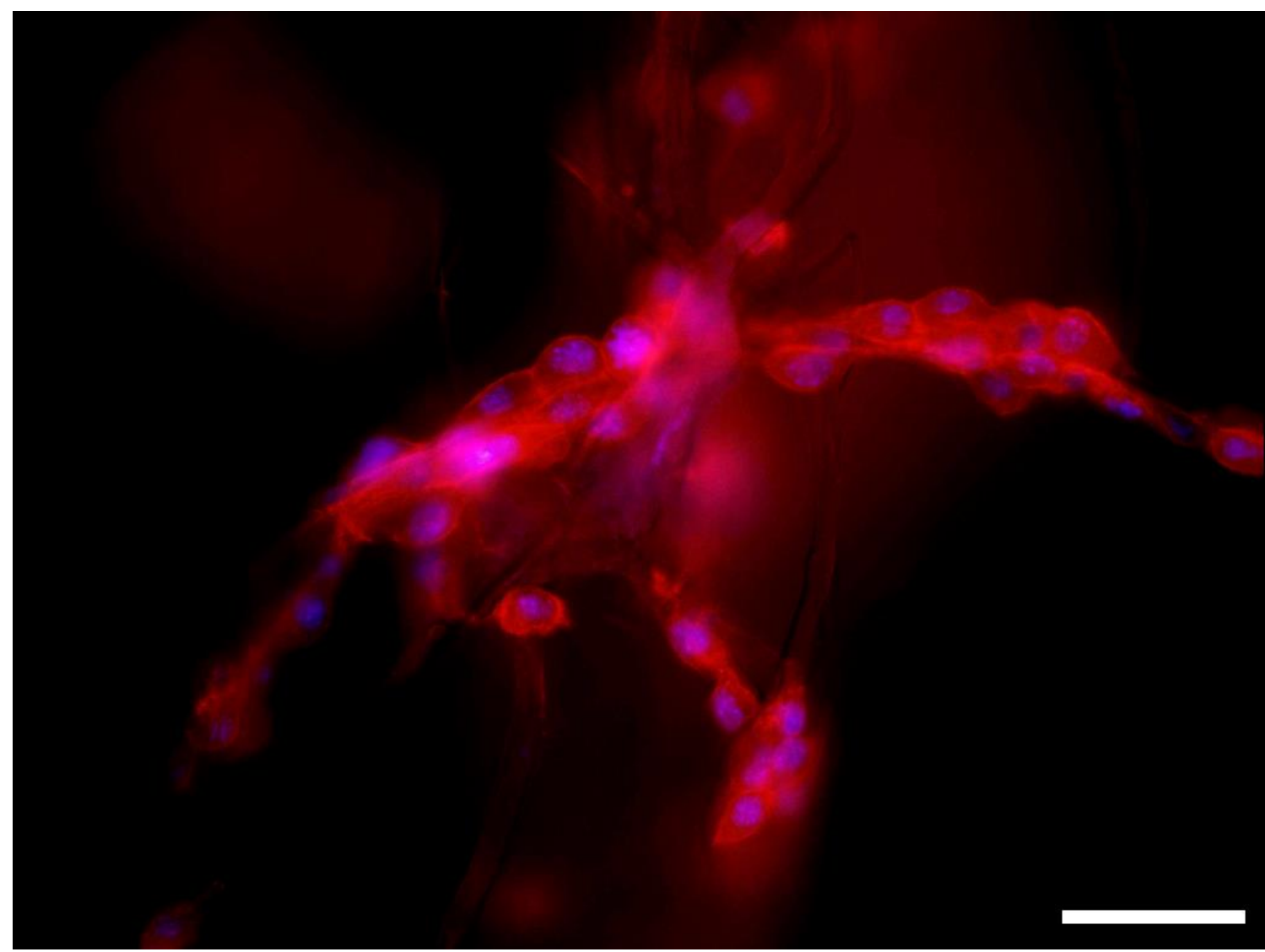


Figure 8 (g)

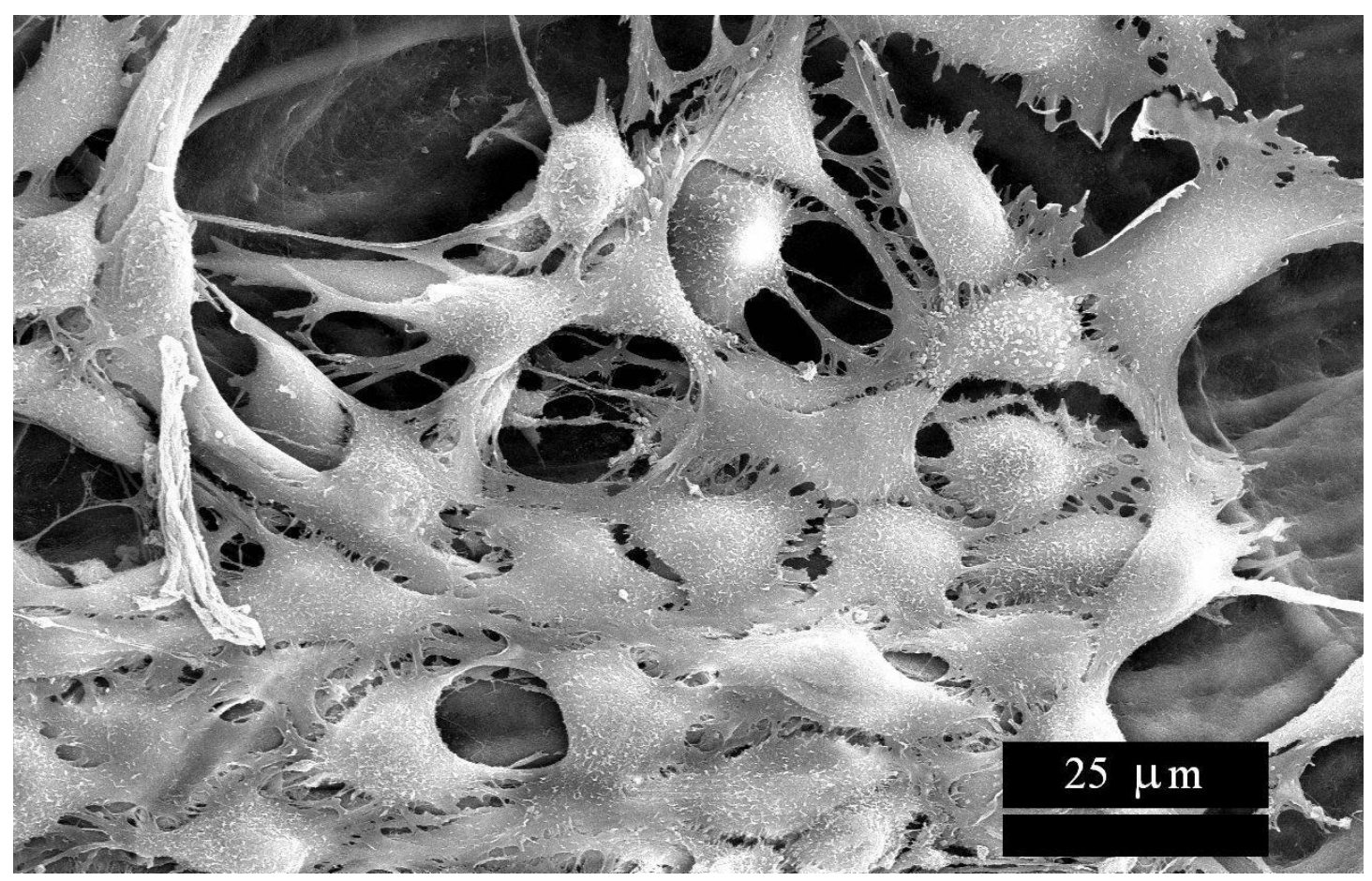

Figure 8 (h)

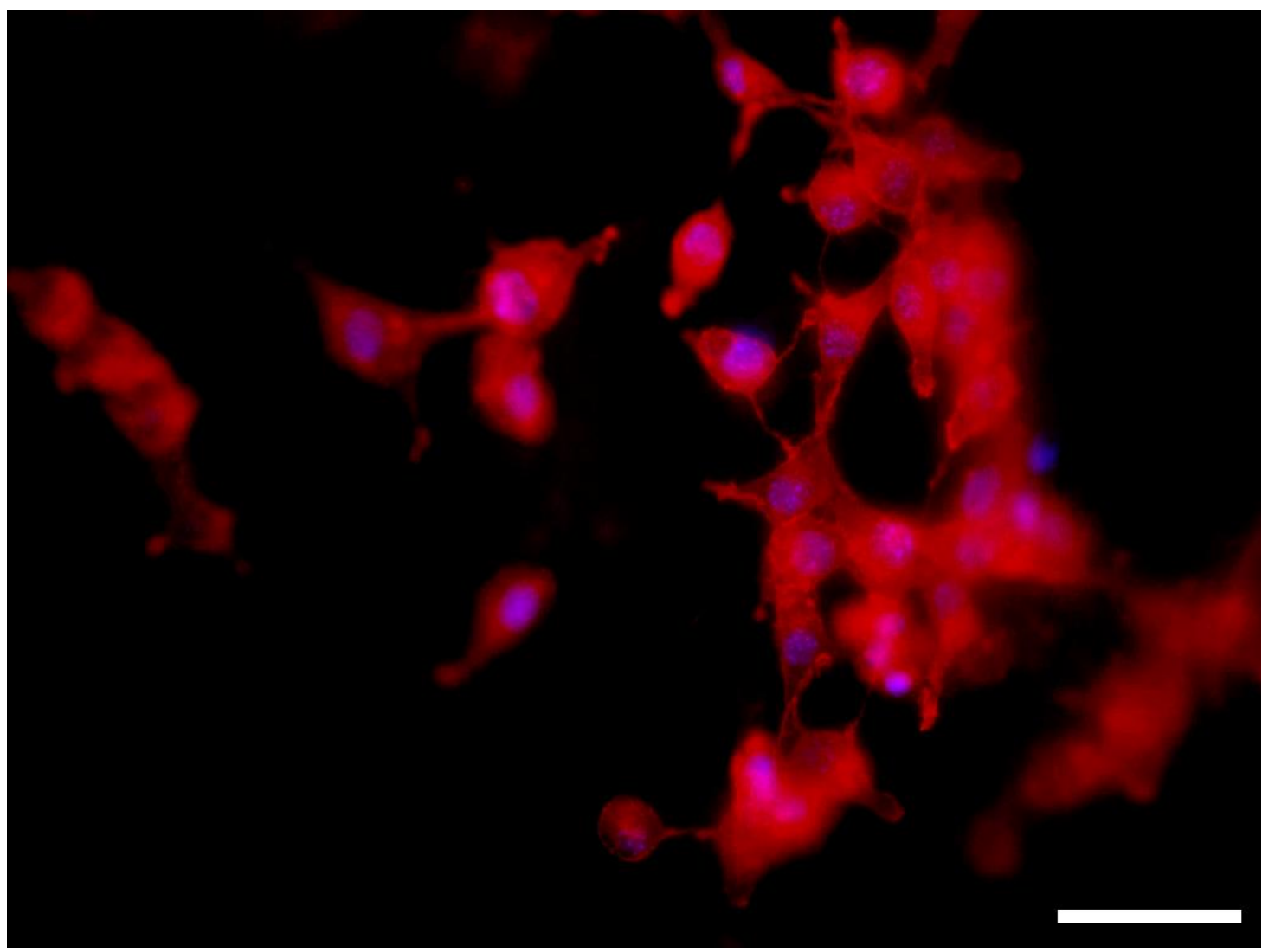

